\title{
Cambio en el régimen de gobierno: un conflicto en la Provincia peruana de la Compañía de Jesús (1697-1703)
}

\author{
Trilce Laske ${ }^{1}$
}

Recibido: 7 de febrero de 2019 / Aceptado: 11 julio de 2019

Resumen. Este texto analiza el conflicto que dividió la Provincia peruana de la Compañía de Jesús entre los años de 1697 y 1703. Su objetivo es doble. Por una parte, se trata de recalcar el interés para la investigación sobre Ordenes o corporaciones de herramientas procedentes del análisis de redes o de la sociología de las organizaciones. Por otra, pretende matizar el valor explicativo del criollismo, proponiendo a la luz del caso estudiado otro patrón interpretativo para las décadas finales del siglo XVII.

Palabras clave: Clientelismo; criollismo; jesuitas; Virrenato; Imperio hispánico; siglos XVII-XVIII.

\section{[en] Change in the Regime: Conflict in the Peruvian Province of the Company of Jesus (1697-1703)}

\begin{abstract}
This article analyzes the conflict that divided the Peruvian Province of the Company of Jesus, between 1697 and 1703. It proposes two objectives: on one hand, it emphasizes the usefullness of tools commonly implemented in networks analysis and organizational sociology, for research on the Orders or Corporations; on the other, it seeks to qualify the explanatory value of Creoleism by proposing another interpretive pattern for the last decades of the $17^{\text {th }}$ century, in light of the case study.
\end{abstract}

Keywords: Clientage; Creoleism; Jesuits; Viceroyalty; Spanish Empire; $17^{\text {th }}-18^{\text {th }}$ Centuries.

Sumario. 1. Introducción. 2. Un gobierno faccionario y clientelista: la Provincia peruana entre 1682 y 1697. 3. Dos lógicas en confrontación: reglamentos contra conspiraciones (1697-1701). 4. Resolución: la victoria del visitador (1702). 5. Conclusión. 6. Referencias bibliográficas. 7. Anexos.

Cómo citar: Laske, T., (2020) Cambio en el régimen de gobierno: un conflicto en la Provincia peruana de la Compañía de Jesús (1697-1703), en Revista Complutense de Historia de América 46, 105-130.

\section{Introducción}

En abril de 1701, la capital limeña fue sacudida por un nuevo episodio del conflicto que oponía dos grupos jesuitas en la Provincia peruana de la Compañía, desde hacía cuatro años. Unas semanas antes, el visitador Diego Francisco de Altamirano había tratado - desde el Cuzco donde se encontraba en una gira de inspección- se-

1 Universidad Nacional Autónoma de México [México]. Programa de becas posdoctorales en la UNAM. Becaria del Instituto de Investigaciones Historicas, asesorada por el Dr. Ivan Escamilla. Orcid: 0000-0003-0717-8410.

E-mail: laske.rosas@gmail.com 
parar de su cargo al rector del colegio de San Pablo, Francisco Xavier Grijalba, en beneficio de Luis de Andrade, uno de sus hombres de confianza. Grijalba formaba parte de la facción contraria al visitador, constituida por importantes jerarcas ignacianos cuyas posiciones se habían visto debilitadas por la política de Altamirano, representante del General. Con el objetivo de impedir la destitución de uno de los suyos, los partidarios de Grijalba movilizaron entonces sus recursos sociales fuera de la institución. Durante todo el mes de abril, solicitaron repetidas veces a sus relaciones en la Corte, el arzobispado y en el Santo Oficio para invalidar la decisión de Altamirano ${ }^{2}$.

En el Virreinato y en Lima en particular, no era entonces inusual que una Orden tuviera un enfrentamiento que entrañase la estrepitosa acción de diferentes implicados. En diciembre de 1680, un conflicto en la Provincia franciscana en torno a la alternancia entre frailes criollos y su comisario peninsular obligó incluso al arzobispo-virrey Liñán a encañonar el convento de San Francisco para desalojar a los amotinados ${ }^{3}$. A diferencia del precedente franciscano y de otros enfrentamientos conventuales, el conflicto jesuita tenía no obstante la particularidad de no provenir de una fractura entre criollos y peninsulares ${ }^{4}$. De hecho, ambos grupos estaban constituidos indistintamente por figuras procedentes tanto de la Península como del Virreinato. Miembro de primera categoría del grupo de jerarcas locales, Francisco Xavier Grijalba era castellano, mientras que el lugarteniente del hombre de Roma, Andrade, era ariqueño 5 .

En ese sentido, este texto se propone demostrar cómo el conflicto jesuita resultó, no de un antagonismo patriótico, sino de la confrontación entre dos modalidades de gobierno en la Provincia ignaciana: una de naturaleza faccionaria de tendencia exógena y otra de orden más institucional y endógena. Primero, señalaremos el monopolio del poder en la institución, a partir de 1682, por una facción poderosa, indiferente a los orígenes y cuyas ramificaciones se extendían más allá del perímetro jesuita. Luego, trataremos el surgimiento del conflicto con la llegada del visitador y con su proyecto para restablecer un funcionamiento saneado en la Provincia, a través de la desarticulación de esta facción, la cual se transformó entonces en un verdadero partido para proteger sus intereses. Finalmente, examinaremos la resolución del enfrentamiento con la victoria de Altamirano y de sus hombres, gracias a herramientas legales. En última instancia, el objetivo general es aquí matizar el valor explicativo del criollismo para los conflictos conventuales en los territorios americanos del Imperio y proponer, con el caso presente, otro patrón interpretativo para el virreinato peruano de final del siglo XVII ${ }^{6}$.

2 El proceder desbordó incluso en la esfera pública: "la presunción que han hecho personas de esfera superior, y de buen juicio, en la Republica, que se ha comunicado a la Plebe diciendo: que el Pe visitador mortifica al padre Xavier". Pleito fiscal del Real Fisco del Tribunal de la Inquisición de Lima con Diego Francisco Altamirano. Madrid, 1701. Archivo Histórico Nacional [España] (en adelante AHN), Inquisición 4786, Exp. 3, f. 69r.

Mugaburu; 1918, t. II: 115.

4 Sobre los conflictos entre religiosos criollos y peninsulares, o analizados como tales, véanse en particular: Lavallé 1982 y 1993. También, por ejemplo: Arrom, 1951; Frost, 1993; Gato Castaño, 1988, entre otros.

5 Todos los datos relativos a lugares y fechas de nacimientos mencionados en este trabajo provienen de los catálogos de la Provincia: Catálogos de la Provincia Peruana, Archivum Romanum Societatis Iesu [Italia] (en adelante ARSI), Perú, 4-11.

6 Para una revisión similar del valor analítico del criollismo en el caso regular, véase para los franciscanos en el Cuzco: Sato, 2014. Véase también el artículo pionero de Acosta sobre el valor del criollismo como factor explicativo para los conflictos eclesiales en general: Acosta, 1984. 


\section{Un gobierno faccionario y clientelista: la Provincia peruana entre 1682 y 1697}

En junio de 1682, quince años antes de la llegada del visitador, el jesuita Martín de Jáuregui fue promovido de manera inesperada al mando de la Provincia peruana. El Provincial en funciones, Fernando de Saavedra, acababa de fallecer prematuramente con 57 años de edad, apenas seis meses después de asumir el cargo ${ }^{7}$. Como rector del primer colegio de la Orden en el Virreinato, el San Pablo de Lima, Jáuregui era el segundo dignatario de la Provincia y su sustituto legal. Con 61 años y originario de Lima, era por entonces un hombre experimentado, que conocía muy bien su institución y a sus miembros. Además del rectorado del San Pablo, el jesuita ya había asumido diferentes ministerios destacados ${ }^{8}$. Se hizo cargo rápidamente de los negocios provinciales. Sin embargo, en vez de suscribirse a una gobernación clásica, el nuevo Provincial aprovechó su inesperada elevación para, durante los meses siguientes, hacerse con el control de la institución. Gracias en particular a una gestión parcial de los ministerios en la Provincia, posicionó a su cabeza a un grupo de jesuitas, viejos amigos y aliados ocasionales, quienes lograrían mantenerse hasta la llegada de Altamirano en Lima en 1697.

Si bien las otras Provincias regulares en el Virreinato poseían, con sus poderosos capítulos provinciales o conventuales y sus mecanismos electorales, una fuerte autonomía regional en término de nombramiento, la Provincia ignaciana dependía no obstante en mayor medida de sus instancias centrales en Roma ${ }^{9}$. En base a consideraciones iniciales de control, el General y sus consejeros detenían pues el monopolio estratégico de los cargos ejecutivos que se renovaban cada tres años (véase cuadro 1). Pero, pese a esas considerables prerrogativas, el nuevo hombre fuerte de la Provincia tenía incluso así una capacidad de gestión considerable. Como Provincial, Jauregui poseía legalmente un significativo abanico de promociones y cargos de directa designación durante su gobierno, algunos de ellos muy cotizados.

Primero, coordinaba la distribución geográfica de sus subordinados, la cual constituía entonces un asunto central en la Provincia. Durante las últimas décadas del siglo, el valor de los ministerios en los grandes centros urbanos sobrepasaba el de espacios apartados a tal punto que, en enero de 1688, el General Tirso consideró establecer estancias obligatorias en las misiones ${ }^{10}$. Segundo, el Provincial gestionaba también los cargos docentes, cuyo impacto era crucial para el desarrollo de las trayectorias en la Orden. El progresivo ascenso de la enseñanza de la gramática a la teología constituía una etapa obligatoria para luego poder acceder a las más altas esferas de autoridad. Para los años de 1680, este cursus honorum encerraba además una dificultad específica en la Provincia peruana en comparación con otros espacios jesuitas (véase cuadro 2). Comportaba pues una dimensión eliminatoria particular-

Saavedra falleció cerca de Ica, durante la visita de la Provincia. Saldamando 1882: 340, Vargas Ugarte, 1963, t. II: 165; Mugaburu, 1918, t. II: 131.

Antes de pasar al rectorado del San Pablo, dirigió el noviciado. También fue consultor de Provincia.

9 Para el caso franciscano, véase: Torre Curiel; 2001: 51-112. Para los dominicos: Serrano Rodríguez, 2014: 64-69.

10 "Tengo pensamiento de establecer que ninguno pueda ascender a los puestos de Prov[incia]l ni de superior de los collegios primeros sin haber pasado por las missiones de Indios, ni tener nicho en Lima ni otra ciudad apetecible si primero no pasa por la prueba del missionero", Carta del General al Provincial Jauregui. Roma, 24-I-1688. ARSI, Perú 2, f. 472v. Véase también: "se arriman nuestros hermanos [...] para que no les saquen de Lima", Vargas Ugarte, 1963, t. II: 169. Para la atractividad de la misión a comienzo del XVII, véase: Maldalsky, 2012. Sobre los misioneros: Borja Medina, 1999. 
mente alta, con una tasa de éxito final reducida por el desbalance entre la cantidad de cátedras y el número de aspirantes locales. Esta situación hacía que los cargos de enseñanza fuesen tanto más preciados en la Provincia en particular ${ }^{11}$. Tercero, si bien no tenían valor ejecutivo, Jauregui administraba el reparto de ministerios prestigiosos por su valor de autoridad, como los prefectos espirituales o los consultores de establecimiento. Los primeros jugaban el papel de guías morales para sus correligionarios, mientras que los segundos operaban como consejeros y observadores de sus superiores ${ }^{12}$.

Finalmente, aunque no era de su competencia directa, Jáuregui como nuevo Provincial disponía también de poderosos mecanismos para influenciar en el reparto romano de los cargos ejecutivos. De manera indirecta, la atribución a nivel local de altos ministerios docentes (como las cátedras de teología o la prefectura de estudios superiores del San Pablo) funcionaba como una señal de preselección para Roma. De manera directa, tenía dentro de sus atributos la obligación de informar al General y a sus consejeros de la calidad de sus subordinados, ya sea a través de recomendaciones epistolares o con las evaluaciones trienales. En cuanto Provincial, el limeño podía incluso en algunos casos valerse del interinato y nombrar superiores provisionales. Según los reglamentos ignacianos, Jáuregui debía obviamente manejar todas estas prerrogativas de acuerdo a criterios imparciales y utilitaristas o meritocráticos. No obstante, para el nuevo hombre fuerte de la Provincia, constituyeron instrumentos de poder tanto para beneficiar a los suyos como para obtener el beneplácito de aliados y clientes.

Cuadro 1. Facultades de nombramiento directo en la Compañía de Jesús por Provincia ${ }^{13}$.

\begin{tabular}{|c|c|c|c|}
\hline & Sede central romana & Provincial & Rector \\
\hline Nombramientos & $\begin{array}{l}\text { - Provincial } \\
\text { - Rectores/Superiores } \\
\text { - Procurador de } \\
\text { Provincia } \\
\text { - Consultores } \\
\text { provinciales }\end{array}$ & $\begin{array}{l}\text { - } \text { Socio } \\
\text { - Consultores de colegio/ } \\
\text { casas } \\
\text { - Procuradores de } \\
\text { colegio/casas } \\
\text { - Ministros de colegio/ } \\
\text { casas } \\
\text { - Prefectos espirituales } \\
\text { - Prefectos de estudios } \\
\text { - Ministerios } \\
\text { - Profesores } \\
\text { - Predicadores } \\
\text { - Misioneros... }\end{array}$ & $\begin{array}{l}\text { - Prefecto de Iglesia } \\
\text { - Prefecto de academia } \\
\text { - Prefecto de biblioteca } \\
\text { - Oficios de los } \\
\text { coadjutores }\end{array}$ \\
\hline
\end{tabular}

11 En 1695, la Provincia contaba por ejemplo con solo 10 cátedras de teología (tres en la Plata y el Cuzco, cuatro para el San Pablo) para más de 100 profesos. Esta situación llevó Diego de Eguíluz a señalar en enero de 1701 como: "el no leer [teología] los que llegan al grado de profesos [en la Provincia peruana], es defecto accidental, pues nace de $[\ldots]$ no aver cátedras para tantos". Pleito fiscal del Real Fisco del Tribunal de la Inquisición de Lima con Diego Francisco Altamirano. Madrid, 1701. AHN, Inquisición 4786, Exp. 3, f. 50r.

12 Para la importancia de la prefectura espiritual en el siglo XIX, véase: Revuelta, 1998: 304-314.

13 Elaboración propia en base a: Demoustier, 1995: 23. 
Cuadro 2. Equilibrio demográfico en las Provincias de Perú, Nueva España y Austria en 1690 (tensiones en la Provincia peruana) ${ }^{14}$.

\begin{tabular}{|c|c|c|c|}
\hline & Perú & Nueva España & Austria \\
\hline Miembros & $496-221$ sacerdotes & $451-232$ sacerdotes & $1105-467$ sacerdotes \\
\hline Establecimientos & $\begin{array}{l}\quad 25 \\
18 \text { colegios } \\
4 \text { residencias } \\
2 \text { misiones }\end{array}$ & $\begin{array}{l}\quad \quad 31 \\
20 \text { colegios } \\
4 \text { residencias } \\
11 \text { misiones }\end{array}$ & $\begin{array}{l}\quad 55 \\
26 \text { colegios } \\
15 \text { residencias } \\
14 \text { misiones }\end{array}$ \\
\hline Puestos directivos & $\begin{array}{c}26 \\
\text { Sacerdotes/puesto 8,5 }\end{array}$ & $\begin{array}{c}32 \\
\text { Sacerdotes/puesto } 7,4\end{array}$ & $\begin{array}{c}56 \\
\text { Sacerdotes/puesto } 8,4\end{array}$ \\
\hline Cátedras de teología & $\begin{array}{c}10 \\
\text { Sacerdotes/cátedra } 22\end{array}$ & & $\begin{array}{c}30 \\
\text { Sacerdotes/cátedra } 15,5\end{array}$ \\
\hline $\begin{array}{l}\text { Otros docentes } \\
\text { titulares }\end{array}$ & $\begin{array}{l}\quad 25 \\
\text { Sacerdotes/cargo } \\
\text { docente } 8,8\end{array}$ & Sin dato & $\begin{array}{l}101 \\
\text { Sacerdotes/cargo } \\
\text { docente 4,6 }\end{array}$ \\
\hline
\end{tabular}

En base a sus nuevas competencias, Martín de Jáuregui empezó por infiltrar la alta jerarquía provincial (lazos horizontales). La estrategia del jesuita era de doble vía. Se trataba de fortalecer su margen de gobernabilidad local y de controlar los canales de comunicación con Roma. Por ello, se dedicó a colocar en puestos claves a amigos y socios, mientras que se esforzaba en negociar la adhesión, duradera o pasajera, de otros miembros de la élite dirigente ignaciana. De hecho, para abril de 1685, unos tres años después de asumir el Provincialato, Jáuregui ya tenía cumplidos con sus objetivos (véanse cuadros 3 y 4) ${ }^{15}$. A nivel de la gobernación local, su socio y mano derecha, Nicolás de Olea, era un incondicional. Sobre todo, gracias al mecanismo excepcional del interinato, varios seguidores del nuevo Provincial dirigían colegios esenciales dentro de la estructura provincial ${ }^{16}$. El Colegio del Callao se encontraba en las manos de Juan de Yáñez. En Lima, Jáuregui había encomendado el rectorado del San Pablo a Francisco Xavier Grijalba, lo cual le garantizaba el dominio temporal del primer establecimiento jesuita del Virreinato. A nivel de los vínculos con el General, Martín de Jáuregui controlaba en 1685 la Consulta de Provincia, instancia de vigilancia para Roma ${ }^{17}$. En cuanto socio y rector del San Pablo, Olea y Grijalba formaban automáticamente parte de ella. Los otros dos miembros, Juan del Castillo e Ignacio de las Roelas, procedían en cambio de nombramientos romanos. Jáuregui había obtenido su adhesión a cambio de ministerios prestigiosos: Del Castillo era vice-rector del San Pablo y Roelas su prefecto espiritual.

14 Elaboración propia. Para la provincia de Perú: Catálogo trienal de 1690, ARSI, Perú 4-11. Para Austria, véase: Lukács, 1990, V. Para la Nueva España: Catálogo trienal de 1690, Archivo Histórico de la Provincia Mexicana [México].

15 Desgraciadamente, el ARSI no cuenta con el catálogo breve de 1682, por lo cual solo nos hemos podido basar en el de abril de 1685 .

16 En el catálogo breve de 1685, están presentados como los sustitutos provisorios de los rectores oficiales ("rector renuntiatus, proximus itineri"). No hemos observado el procedimiento en otros catálogos. Además del San Pablo y del Callao, ocurre lo mismo con Juan de Aranceaga en Oruro y Pedro de Alvarado en Trujillo.

17 Sus miembros tenían la obligación de escribir cada seis meses al General. 
En paralelo al control de la jerarquía provincial, Martín de Jáuregui empleó la distribución de los ministerios para alimentar retículas de allegados y obligados en la institución, los cuales funcionaban como soportes y canales de su autoridad (lazos verticales). Además de los ministerios en Lima, los cargos docentes, cátedras y prefecturas de estudio, representaron recursos estratégicos para el nuevo Provincial debido a su escasez e impacto sobre las trayectorias. Cumbre de la jerarquía docente, la prefectura de los estudios superiores del San Pablo fue atribuida al arequipeño Diego de Eguíluz. De menor prestigio, la del Cuzco recayó sobre Nicolás de Torres. Al mismo tiempo, Martín de Jáuregui distribuyó las disputadas cátedras de teología a clientes como Nicolás de Miraval o Juan de Ibargoyen. E1 Provincial aceleró también la progresión de José de Aguilar, promoviéndolo de la enseñanza de gramática a filosofía. En paralelo, Jáuregui usó también las consultorías y prefecturas espirituales para congraciarse con jesuitas como Juan de Larrea o Juan de Barrasa. De ese modo, para mediados de 1685, el Provincial no solo tenía conquistada la alta élite sino también había posicionado a sus clientes en los ministerios más preciados de la institución (véase cuadro 4).

Pero si bien resultó exitoso, este apoderamiento era no obstante aún frágil, puesto que dependía en gran parte de las decisiones romanas. A finales de 1685, Jáuregui trató pues de perennizar las posiciones adquiridas ante Roma. Además de recomendaciones epistolares, el Provincial instrumentalizó las evaluaciones obligatorias de sus subordinados ${ }^{18}$. En vez de seguir un procedimiento normal, manipuló los cuadernos enviados al General. Jáuregui atribuyó las calificaciones más positivas de la Provincia a sus seguidores y aliados, quienes destacaron entonces en todo, por encima de sus correligionarios (véase cuadro 7). De hecho, la sede central de la Compañía respetó las indicaciones enviadas desde Lima. Para el trienio de 1689, el nuevo equilibrio de las fuerzas en la Provincia fue ampliamente avalado. En efecto, el nuevo organigrama directivo resultó muy favorable para Jáuregui (véanse cuadros 3 y 4). El General no solo mantuvo a sus principales allegados y aliados dentro de la élite dirigente, sino que elevó por primera vez a una parte de sus protegidos a cargos de autoridad. Los primeros colegios de la Provincia, el San Pablo y el Noviciado, recayeron en Yáñez y Sotomayor. Por primera vez en su trayectoria, Nicolás de Olea obtuvo un rectorado, como Miraval, Quiroz y Aguilar ${ }^{19}$. Sobre todo, el rector interino del San Pablo y aliado de Jáuregui, Francisco Xavier Grijalba, fue designado para sucederle al Provincialato.

¿Cómo explicar la decisión romana de seguir hasta este punto las recomendaciones enviadas desde Lima? Las instancias ignacianas captaron sin duda, aunque solo en parte, la situación debido a sus décadas de experiencia. Sin embargo, parece que, así como para otras Provincias, el General y sus consejeros se inclinaron, en base a consideraciones de eficiencia gubernamental, a valorar más la armonía interna que la amenaza del favoritismo ${ }^{20}$. Ya sea por aprecio profesional o por clientelismo, un

18 Desgraciadamente, las recomendaciones epistolares no se han conservado para el caso de la Provincia peruana, solo quedan las evaluaciones trienales que permiten reconstituirlas. La Provincia de México conserva más datos, véase: Epistolario General. ARSI, México 3.

19 Olea obtuvo el importante rectorado del Cuzco. Durante su estancia, el jesuita se vio involucrado en una violenta controversia pública con otros regulares que merecería un estudio detenido. Cf. Manuscritos de la Colección Vargas Ugarte. Cuzco (1691-1692). Universidad Ruiz de Montoya [Perú] (en adelante CVU], T. 15, doc. 1, $2,3$.

20 Al parecer, hubo fenómenos similares en la Provincia de Austria, lo cual lleva a la hipótesis que más que individuos, el general y sus consejeros escogían equipos a la hora de atribuir los puestos directivos provinciales. 
equipo dirigente unido resultaba más seguro que un grupo dividido. De ese modo, las instancias romanas ofrecieron una ratificación a Jáuregui. A comienzos de 1689, lo que no era más que un grupo de jesuitas en torno al limeño se convirtió pues en una verdadera facción, que lograba adjudicarse los principales puestos directivos.

Cuadro 3. Primeros dirigentes de la Provincia durante los años 1690 (alto índice de continuidad $)^{21}$.

\begin{tabular}{|c|c|c|c|c|}
\hline Trienios & 1685-dic.1688 & Ene.1689-dic.1691 & Ene.1692-dic.1694 & Ene.1695-dic.1697 \\
\hline \multicolumn{5}{|c|}{ Directorio } \\
\hline Provincial & M. Jáuregui (Lima) & $\begin{array}{l}\text { FX Grijalba } \\
\text { (Castilla) }\end{array}$ & J. Yáñez (Castilla) & $\begin{array}{l}\text { D. Eguíluz } \\
\text { (Arequipa) }\end{array}$ \\
\hline $\begin{array}{l}\text { Socio } \\
\text { provincial }\end{array}$ & N. Olea (Huánuco) & F. Tardío (Lima) & $\begin{array}{l}\text { D. Eguíluz } \\
\text { (Arequipa) }\end{array}$ & F. Tardío (Lima) \\
\hline Administrador & M. Mendez (Bilbao) & M. Orellana (Pisco) & M. Orellana (Pisco) & M. Orellana (Pisco) \\
\hline Procurador & $\begin{array}{l}\text { U. Cespedes } \\
\text { (Huánuco) }\end{array}$ & $\begin{array}{l}\text { Goycochea } \\
\text { (Virreinato) }\end{array}$ & s.d. & $\begin{array}{l}\text { Goycochea } \\
\text { (Virreinato) }\end{array}$ \\
\hline \multicolumn{5}{|c|}{ Principales colegios } \\
\hline $\begin{array}{l}\text { Rector San } \\
\text { Pablo }\end{array}$ & $\begin{array}{l}\text { FX Grijalba } \\
\text { (Castilla) }\end{array}$ & J. Yáñez (Castilla) & N. Olea (Huánuco) & $\begin{array}{l}\text { J.Sotomayor } \\
\text { (Huamanga) }\end{array}$ \\
\hline $\begin{array}{l}\text { Rector } \\
\text { noviciado }\end{array}$ & M. Oña (Aragón) & $\begin{array}{l}\text { J.Sotomayor } \\
\text { (Huamanga) }\end{array}$ & $\begin{array}{l}\text { FX Grijalba } \\
\text { (Castilla) }\end{array}$ & J. Yáñez (Castilla) \\
\hline $\begin{array}{l}\text { Rector } \\
\text { Cercado }\end{array}$ & S Valente (Napoles) & $\begin{array}{l}\text { F. Bazán } \\
\text { (Chachapoya) }\end{array}$ & s.d. & $\begin{array}{l}\text { FX Grijalba } \\
\text { (Castilla) }\end{array}$ \\
\hline \multicolumn{5}{|c|}{ Consulta de Provincia } \\
\hline Consultores & $\begin{array}{l}\text { N. Olea (Huánuco) } \\
\text { FX Grijalba } \\
\text { (Castilla) } \\
\text { J. del Campo } \\
\text { (Cuzco) } \\
\text { Ig. De las Roelas } \\
\text { (Areq) }\end{array}$ & $\begin{array}{l}\text { F. Tardío (Lima) } \\
\text { J. Yáñez (Castilla) } \\
\text { De las Roelas } \\
\text { (Arequipa) } \\
\text { U. Céspedes } \\
\text { (Huánuco) } \\
\text { G. España (Lima) } \\
\text { J.Sotomayor } \\
\text { (Huamanga) } \\
\text { M. Jáuregui (Lima) }\end{array}$ & s.d. & $\begin{array}{l}\text { F. Tardío (Lima) } \\
\text { J. Yáñez (Castilla) } \\
\text { U. Céspedes } \\
\text { (Huánuco) } \\
\text { J.Sotomayor } \\
\text { (Huamanga) } \\
\text { M. Jáuregui (Lima) } \\
\text { FX Grijalba } \\
\text { (Castilla) }\end{array}$ \\
\hline
\end{tabular}

Lukács, 1990, t. V.

${ }^{21}$ Elaboración propia en base a los catálogos breves de 1690 y 1695 . El catálogo breve de 1693 no se encuentra en el ARSI, por lo cual nos basamos en los datos incompletos de Saldamando. Los cargos de administrador y socio eran atribuidos a nivel de la Provincia. ARSI, Perú 4-11. 
Una vez en funciones, Grijalba prolongó en efecto las prácticas y orientaciones de su predecesor. Primero, como nuevo Provincial, tendió a asignar los ministerios que le incumbían a las mismas retículas de aliados y clientes construidas por Jáuregui (véase cuadro 4). Asimismo, a la luz del número inusualmente alto de consultores provinciales, recurrió probablemente a nombramientos interinos para la Consulta, la cual se vio monopolizada por los principales dignatarios de su facción ${ }^{22}$. Luego, en 1690, Grijalba volvió a emplear la estrategia de manipulación de las evaluaciones internas. Las mismas figuras se beneficiaron nuevamente de calificaciones altas $\mathrm{y}$, otra vez, Roma les prorrogó los cargos gubernamentales, en 1692, para el trienio siguiente. En 1695, el mecanismo se volvió a desplegar con éxito. El nuevo Provincial escogido por el General fue Diego de Eguíluz. Los colegios de Lima recayeron en los miembros de la misma facción: Grijalba, Yáñez y Sotomayor, mientras que algunos de sus allegados subieron en la escala de los rectorados con los del Cuzco y del Callao. En la Provincia, los ministerios cotizados continuaron siendo distribuidos entre sus clientes y allegados.

Cuadro 4. Miembros identificados de la facción al poder entre 1682-169723.

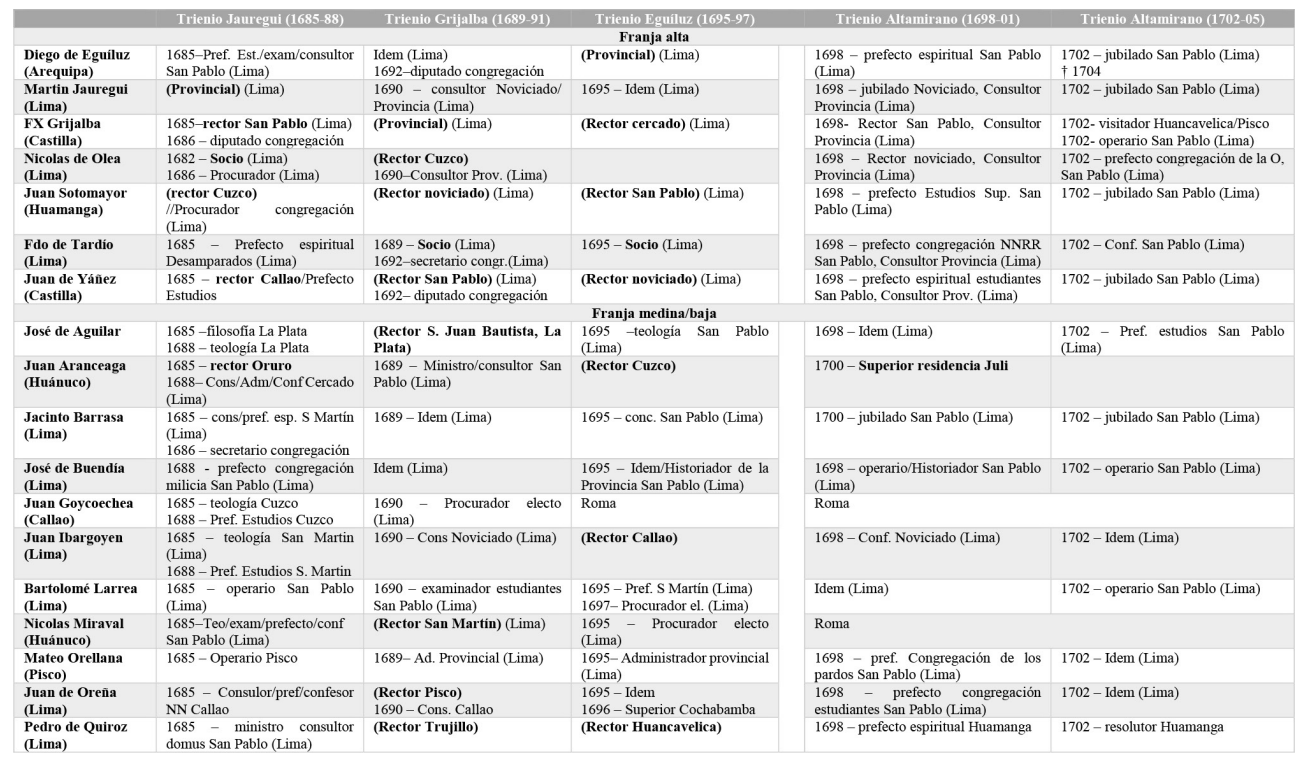

Gracias a su gestión clientelista, la facción jesuita logró mantenerse quince años a la cabeza de la Provincia. Aunque contradecía la lógica institucional de la Compañía, tal situación no fue no obstante inédita. En el Imperio hispánico, la construcción de redes de aliados y clientelas constituyeron un modo de funcionamiento usual ${ }^{24}$.

22 Los consultores solían ser tres o cuatro en todas las Provincias, pero durante el Provincialato de Grijalba llegaron inusualmente a siete (véase cuadro 4). Al llegar Altamirano, su número volvió a bajar en cuatro.

23 Elaboración propia en base a los catálogos breves. Entre paréntesis vienen los nombramientos romanos. ARSI, Perú 4-11.

24 Cañeque, 2005; Ibarra, 2007; Yun Casalilla, 2009. 
Dentro del espacio conventual mismo, la Provincia agustina de la Nueva España conocía por ejemplo al mismo tiempo fenómenos similares. Una figura como el novohispano Velázquez de la Cadena se hizo con el control de su institución gracias a retículas clientelistas, afianzadas por el reparto de prioratos y de otros cargos ${ }^{25}$. Pero si bien en décadas anteriores la Provincia había conocido fenómenos de afirmación criolla ${ }^{26}$, la facción era no obstante indiferente a la cuestión patriótica para el periodo, a diferencia de la situación agustina. Al contrario, en su composición, reflejaba la diversidad de los orígenes de los jesuitas en la Provincia, como sus proporciones (véanse cuadros 3 y 4). Asimismo, sus miembros se relacionaban en el Virreinato tanto con criollos como peninsulares (véase cuadro 5). En realidad, la facción se constituyó sobre un ensamblaje heteróclito y dinámico de otros vínculos, basados en dos lógicas complementarias: una lógica institucional (interna) y una lógica de influencia (externa).

Por un lado, la facción resultó de una agregación de múltiples alianzas o acuerdos internos, establecidos en base a coordenadas propias de la institución: las posiciones jerárquicas y las posiciones oficiosas. Las posiciones jerárquicas correspondían al poder formal y a la legitimidad oficial. En su más alto nivel, el nexo entre el limeño Jáuregui y el castellano Grijalba resultó de una vinculación exitosa fundada por ambas partes a partir de consideraciones institucionales. Para 1682, Grijalba era un jerarca prestigioso y reconocido por Roma, pero mal arraigado por haber permanecido fuera de Lima y de la Provincia por más de 15 años $^{27}$. Para el nuevo Provincial Jáuregui, el castellano representaba un hombre nuevo que se beneficiaba del aprecio romano. Sobre esta base, los dos jesuitas se asociaron y cambiaron ministerio contra lealtad. Las posiciones oficiosas correspondían al poder informal en la Provincia, el cual se medía según las capacidades oficiosas de acción. En 1676, el General Giovanni Oliva señaló uno de los fundamentos de este tipo de poder: el patronazgo intergeneracional. Para Oliva: "las causas de haber descaecido aquel fervor y celo primitivo [...] son los patrocinios, filiaciones y dependencias de los Padres antiguos, a los cuales se arriman nuestros hermanos para que los defiendan y los favorezcan" ${ }^{28}$. Por haber sido entre otras cosas instructor para la 3era probación, Diego de Eguíluz tenía una gran influencia interna basada en parte sobre este mecanismo. Sobre esta base, por 1682, Jáuregui y el arequipeño juntaron fuerzas ${ }^{29}$.

Por otro lado, la facción fue atravesada permanentemente por fuerzas exógenas, las cuales añadieron a la retícula institucional otros tipos de nexos. Así, la facción fue moldeada en parte por las lógicas de linaje, las cuales prolongaron en la Provincia complicidades o ambiciones externas. De hecho, el mecanismo se observaba también en la vecina Provincia jesuita del Nuevo Reino ${ }^{30}$. En la esfera alta de la facción, Jáuregui y su mano derecha, Nicolás de Olea, se encontraban unidos por intereses familiares acor-

\footnotetext{
25 Rubial, 1990.

26 Coello de la Rosa, 2008.

27 Luego de dirigir durante ocho años, de 1666 a 1674, la residencia apartada del Juli, Grijalba fue mandado por el General a la Provincia de Chile como vice-Provincial. Regresó a Lima en 1681.

28 Vargas Ugarte, 1963, t. II: 169.

29 Como patrón, Eguíluz se asoció a Jauregui a la manera de un racimo: integró en el acuerdo a sus clientes. Obtuvo que Pedro de Quiroz fuese nombrado como su propio ministro en el San Pablo. Nicolas de Torres obtuvo la prefectura de Estudios del Cuzco. En 1688, Eguíluz consiguió colocar en el Colegio de Arequipa otro cliente suyo, Martín de Iraola, quien funcionó muy probablemente como su mano derecha en su ciudad natal.

30 Jouanen, 1941: 283.
} 
dados por sus padres peninsulares ${ }^{31}$. El mismo Olea estaba emparentado con el joven José de Aguilar. En su esfera mediana y baja, la facción incorporó a hermanos, tales como los Iraola y los Orellana, los cuales desdoblaban su capacidad de acción ${ }^{32}$. Sobre todo, la facción fue siempre sensible al contexto político en el Virreinato y a la posición de los grupos de poder. De manera oportuna, procuró repercutir en su propio entramado las configuraciones externas y sus cambios. El objetivo era favorecer tanto los intereses de la facción como los intereses individuales o familiares de sus integrantes.

En base a consideraciones de eficiencia, la facción incorporó por ejemplo a los hermanos Larrea. Miembros de un poderoso linaje, los Larrea poseían grandes recursos económicos que invirtieron en parte en la restauración del San Pablo ${ }^{33}$. Por su madre, Ana de la Celda, estaban estrechamente vinculados con la Audiencia y el cabildo lime$\tilde{n}^{34}$. Por su padre, mantenían vínculos útiles con algunos funcionarios inquisitoriales ${ }^{35}$. A cambio de la benevolencia familiar, su incorporación a la facción les garantizó una sedentarización en Lima y aceleró sus progresiones en la Orden. En las evaluaciones trienales destinadas a Roma, Bartolomé de Larrea pasó así de "sin talento" a calificaciones destacadas que lo llevarían hasta la Procuraduría provincial ${ }^{36}$. Tras el cambio de gobierno en el Virreinato, la facción integró también al jesuita José de Buendía, por haber logrado granjearse los favores del nuevo virrey gracias a su oratoria ${ }^{37}$. Su cercanía con el Conde de la Monclova constituía una valiosa ventaja política.

De 1682 hasta la llegada del visitador, la facción jesuita constituyó pues una nebulosa dinámica. Por una parte, se edificó en base a un ensamblaje de alianzas y de acuerdos internos. Por otra, fue moldeada permanentemente por parámetros externos a la Provincia, los cuales le ofrecieron un poderoso arraigo local, con criollos como peninsulares. En ambos casos, lo que la estructuró fueron principalmente las posiciones de sus integrantes, quienes podían llevar objetivos distintos. De hecho, solo Altamirano conseguiría unirlos contra él en un proyecto común que los transformaría en un verdadero partido.

31 En 1637, Domingo de Olea, padre de Nicolas, testificó de la limpieza de sangre de Martín de Jauregui para que ingresase en la Compañía. Información de filiación y limpieza de sangre de Martín de Jáuregui. Lima, 1637. CVU, Tomo 20, doc. 24.

32 Los Iraola eran dos, Martín y Gabriel. Fueron clientes de Eguíluz, quien empleó a Gabriel en su directorio en 1695. Los Orellana eran tres en la Orden, Mateo, Antonio y Miguel. Durante el conflicto con Altamirano, Miguel sirvió de espía, a través de su hermano, para el grupo de opositores jesuitas en Lima: "como se sabe en todo este colegio de san pablo, por carta escrita del Pe Migl de Orellana catedrático de prima de aquel colegio a su hermano el Pe Mateo de Orellana". Pleito fiscal del Real Fisco del Tribunal de la Inquisición de Lima con Diego Francisco Altamirano. Madrid, 1701. AHN, Inquisición 4786, Exp. 3, f. 76r.

33 "Renunciación del Padre Blas de Larrea de la Compañia de Jesús", Biblioteca Nacional del Perú [Perú] (en adelante BNP), Manuscritos, B922.

34 Su madre fue hija de Juan de la Celda, Oidor de Lima. Su tío y su primo, Juan Celda Verdugo y Luis Vega y Celda, fueron alcaldes y regidores de Lima. A nivel de la Audiencia, además del abuelo Oidor, la hermana de los hermanos Larrea, María de la Rea y Celda, tuvo como testigo de boda a Juan Bautista Morote, fiscal de la Audiencia.

35 Procedente de la Península, su padre, Bartolomé Osava de Larrea, fue caballero de Calatrava, contador del tribunal de la Inquisición y del tribunal de Cuentas. Según Altamirano y su grupo, fue por el Inquisidor Valera que Bartolomé de Larrea obtuvo el nombramiento de procurador provincial bajo el gobierno de Eguíluz. Pleito fiscal del Real Fisco del Tribunal de la Inquisición de Lima con Diego Francisco Altamirano. Madrid, 1701. AHN, Inquisición 4786, Exp. 3, f. 3r.

36 En 1678, fue evaluado como "sin talento". Diez años después, en 1688, el cambio era radical: "Ingenio muy bueno, Juicio bueno, Prudencia buena, Experiencia alguna, [...] Talento lectura/gobierno". Catálogos trienales secretos. Lima, 1678-1688. ARSI, Lima 5.

37 Sobre Buendía, véase: Estenssoro, 2003; Laske, 2019. 
Cuadro 5. Ramificaciones externas identificadas entre 1682 y 1697

(amplitud social alta) ${ }^{38}$.

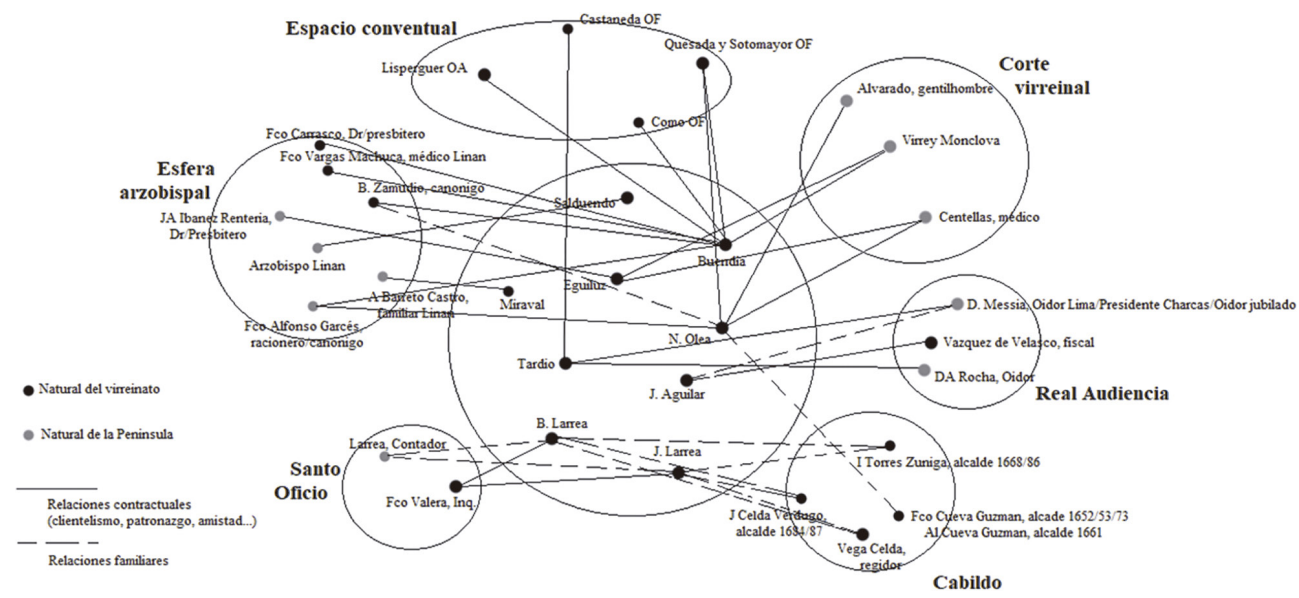

Si bien logró perennizarse, el monopolio de los ministerios por parte de una facción interna apartó obviamente hacia las márgenes de la Provincia a un amplio abanico de jesuitas, situados fuera de los circuitos internos de patronazgo o desprovistos de influyentes protecciones externas. Bloqueó por ejemplo las trayectorias de miembros prometedores tales como los jóvenes Luis de Andrade y Alonso de Messia, ambos criollos de segunda generación (véase cuadro 9). Con la llegada al poder del grupo de Jáuregui, sus ascensos en la institución se estancaron. Nacido en Arica el 25 de agosto de 1653, Luis de Andrade pertenecía a la misma generación que José de Aguilar, miembro de la facción jesuita ${ }^{39}$. Los dos hombres se cruzaron en el noviciado y compartieron en 1681 cargos docentes menores en el San Pablo ${ }^{40}$. Sin embargo, cuando Aguilar obtuvo en 1687 una cátedra de teología y una evaluación excelente, Andrade fue mantenido en la enseñanza de filosofía con calificaciones mediocres $^{41}$. En 1690, fue relegado incluso a un simple cargo de operario, lo cual interrumpió provisionalmente su ascenso dentro del cursus honorum ignaciano. Dos años más joven, Alonso de Messia conoció una situación similar ${ }^{42}$. Como Andrade, el jesuita esperó unos diez años en el San Pablo antes de poder pasar de la filosofía a

38 Elaboración propia. Usamos datos familiares como partidas de bautismo (Archivo Arzobispal de Lima) y los documentos de renuncia a heredar (Biblioteca Nacional del Perú y AGN). También los documentos del AGI ofrecieron indicios documentales. Finalmente, los paratextos de publicación proporcionaron informaciones, como las dedicatorias o las aprobaciones.

39 Los padres de Andrade fueron Lope de Andrade y Sotomayor, natural de Potosí, y Ana Salgado de Araujo, natural de Arica. Información genealógica de Luis de Andrade. Madrid, 1696. AHN, Inquisición 1575, Exp. 796. La familia paterna de Andrade estaba bien enraizada en Potosí. Su tío, Luis de Andrade y Sotomayor, fue corregidor de la provincia de los Chimas, gobernador de Chocaya y alcalde mayor de minas. Informaciones de Luis de Andrade y Sotomayor. Potosí, 1656.Archivo General de Indias [España] (en adelante AGI), Charcas 95, N.18.

40 Andrade entró en 1667 en la Compañía, Aguilar el año anterior.

41 En 1685, el catálogo secreto indicaba para Aguilar: "Ingenio muy bueno, jucio muy bueno, prudencia muy buena, experiencia mediana". Para Andrade: "Ingenio muy bueno, juicio mediano, prudencia mediana, experiencia poca", Catálogo trienal secreto. Lima, 1685. ARSI, Perú 5, f. 397.

42 Nació el 12 de enero de 1655 en Lima. Sus padres fueron Francisco Messia Ramon, de Quito y Francisca Bedoya, de Lima. 
la teología. Excluidos del reparto de cargos en la Provincia, ambos jesuitas criollos no dudaron en apoyar al visitador peninsular Altamirano y su voluntad de reforma.

\section{Dos lógicas en confrontación: reglamentos contra conspiraciones (1697-1701)}

Unos quince años después de la inesperada promoción de Jáuregui al Provincialato, el 27 de marzo de 1697, el visitador Diego Francisco de Altamirano llegó a Lima ${ }^{43}$. Encargado de inspeccionar la Provincia peruana, el recién llegado era un importante jerarca con una amplia experiencia en su Orden y con conexiones al más alto nivel. Oriundo de Castilla pero formado en la Provincia paraguaya, había sido sucesivamente Provincial, procurador provincial y luego procurador general de Indias en Madrid $^{44}$. Gracias a sus diferentes labores, Altamirano guardaba contactos en la Corte ${ }^{45}$. Sobre todo, el jesuita era un hombre de confianza del General Tirso de González, a quien conoció antes de su elección al Generalato en $1687^{46}$. Para la visita de la Provincia, Tirso le delegó incluso todas sus facultades y llegaría a apoyar todas las acciones que emprendería ${ }^{47}$. Este amplio arsenal legal, así como el respaldo romano, constituyeron precisamente la clave de la victoria de Altamirano sobre la facción jesuita al poder en la Provincia.

Durante sus primeros meses en la capital virreinal, el recién llegado entendió la naturaleza del gobierno en la Provincia y la amplitud de los vínculos de la facción dominante con otras esferas capitalinas. Para el visitador, constituían problemas graves para la institución, que amenazaban su integridad como su vocación. Poco tiempo antes, estando de paso por Quito, ya había señalado al General los graves problemas que implicaban la intromisión de intereses seglares en la Compañía ${ }^{48}$. Con el objetivo de remediarlo, Altamirano desarrolló a partir de finales de 1697 una doble estrategia que fue desplegando en base a sus facultades extraordinarias. Por un lado, trató de eliminar la facción jesuita por medio de su desarticulación. Por otro, se dedicó para compensar a promover miembros hasta entonces marginados o alejados del poder. Al acercarse el final del gobierno del Provincial Eguíluz, el visitador elaboró en este sentido, como representante del General, la nueva lista de rectores. Como nuevo Provincial, se encargó también de distribuir los demás ministerios. Este nuevo reparto, anunciado por diciembre de 1697, constituyó un primer cambio en el equilibrio interno de la Provincia. Sobre todo, fue el detonante del conflicto que la iba a dividir durante unos años ${ }^{49}$.

43 Saldamando, 1882: 222.

44 Altamirano nació en Madrid el 26 de octubre de 1625. Sobre su trayectoria, véase: Aguilar, 1716.

45 Altamirano presumió de ellos ante el virrey de la Monclova: "bien conocido en el R[ea]l Consejo por los muchos negocios que como Procurador G[enera]l de Indias allí trate". Carta de Altamirano a los Inquisidores del Tribunal de Lima. Lima, 1702. CVU, T. 40, doc. 10, f. $1 \mathrm{r}$.

46 Viajaron juntos de Madrid a Roma para la congregación general que eligió a Tirso. Aguilar, 1716: 5 y 21.

47 "Abiendo hecho de mi tanta confianza mi General, [...] y averme dado toda su potestad para poner gobierno, disponer de los súbditos, residenciar Provinciales, poner y quitas superiores locales y rectores, quando y como juzgare yo convenir, aun sin cumplir el Triennio, en la misma forma y manera q puede su Paternidad". Carta de Altamirano a los Inquisidores del Tribunal de Lima. Lima, 1702. CVU, T. 40, doc. 10, f. 1r-v. También: Aguilar, 1716: 24. Sobre el papel institucional de visitador, véase: Philippart, 1968.

48 Jouanen, 1941: 283.

49 Desgraciadamente, el ARSI no conserva el catálogo de 1698. Nos basamos en el catálogo de 1700, hecho el 2 de febrero de 1700 por Altamirano, que corresponde al último año del trienio. 
Como gobernante experimentado, Altamirano apostó en esa fase inicial por una política en gran parte conciliadora. Es probable que el visitador pensase entonces que de ese modo iba a ganarse la obediencia de sus subordinados implicados ${ }^{50}$. Se conformó pues con apuntar al corazón de la facción jesuita y no incluyó en sus medidas a sus círculos de aliados y clientes (véase cuadro 4). El visitador despojó de toda función ejecutiva a la mayoría de los miembros más comprometidos, para relegarlos a ministerios honoríficos, sin poder y sobre todo sin relieve para hombres de su dimensión. Yáñez, Tardío y Sotomayor se vieron rebajados a prefecturas en el San Pablo. Aunque destinado inicialmente por Roma al rectorado del San Pablo, Eguíluz fue relegado también por Altamirano en el colegio limeño ${ }^{51}$. Más perjudicado aun, Martín de Jáuregui fue traslado al noviciado para una jubilación de la cual no salió más. A manera de conciliación, Altamirano mitigó no obstante la dureza de su proceder con respecto a dos integrantes de la facción. Pese a considerables dudas ${ }^{52}$, atribuyó a Grijalba el rectorado del San Pablo, mientras que Nicolás de Olea fue colocado al mando del noviciado. Sobre todo, el visitador los mantuvo a todos en sus cargos de consultores de Provincia. Siendo él representante de Roma, los estimó por error en el momento de orden exclusivamente honorario.

Para compensar la salida de la esfera directiva de estos jerarcas, Altamirano promovió a nuevas figuras. Así como Jáuregui y los suyos, su selección no descansó tampoco en cuestiones de patrias. No solo el visitador se apoyó indiferentemente en naturales del Virreinato como de la Península, sino que miraba con desconfianza a los miembros recién llegados de Europa ${ }^{53}$. En el contexto de finales de 1697, sus prioridades eran la obediencia y la ausencia de connivencia con la facción que se mantenía al poder desde 1682. Para su círculo más íntimo, Altamirano escogió como socio a Nicolás de Figueroa. Originario de Castilla, Figueroa era antes que nada un incondicional del visitador, a quien acompañaba por lo menos desde su salida de Europa en $1688^{54}$. Para el segundo circulo, Altamirano reclutó por una parte a descontentos y a marginados como Luis de Andrade y Alonso de Messia o el castellano Fernando de Aguilar. Por otra, favoreció a miembros alejados de la esfera de influencia de la facción de Jáuregui por haber evolucionado lejos de Lima, tales como los limeños Juan Valdespino y Hernando Colmenero o Diego de Cárdenas, originario del Nuevo Reino ${ }^{55}$. En ambos casos, estos jesuitas vieron sus trayectorias en la Orden acelerarse (véase cuadro 6). Muchos de ellos se vieron promovidos a ministerios gubernamentales, los cuales constituían un asunto estratégico para Altamirano. Según su biógrafo, "su mayor desvelo lo ponía en formar los Rectores, y Superiores de las Casa y Colegios, como quienes son los instrumentos immediatos y necesarios de

50 Aguilar, 1716: 23 .

51 El correo de Roma de 1697 nombraba a Eguíluz como rector del San Pablo. Sin embargo, Altamirano invalidó el nombramiento. En un primer tiempo, pensó pasarlo más bien al rectorado del Cercado antes de mudar de opinión. Vargas Ugarte, 1963, t. II: 306.

52 En esos meses iniciales, Altamirano ya tenía mala impresión de Grijalba. Sus adversarios lo señalarían después: "aver el Pe f x caído de la gracia del Pe visitador, desde que este vajo a Lima de su primera visita, que ha cerca de dos años, y siendo así, que desde entonces, dio a entender a los suyos". Pleito fiscal del Real Fisco del Tribunal de la Inquisición de Lima con Diego Francisco Altamirano. Madrid, 1701. AHN, Inquisición 4786, Exp. 3, f. 79r.

53 Altamirano sospechaba que los mandaban a América por no encajar en sus Provincias europeas. Aguilar, $1716: 27$.

54 Figueroa nació en Talavera el 6 de diciembre de 1661. Los dos hombres salieron juntos de España para América en 1688: Lista de pasajeros. Sevilla, 23-VI-1688. AGI, Contratación 5450, N. 22.

55 Sobre el interés de Altamirano en usar miembros alejados, véase: "no reparaba el P. ni en gastos, ni en passos, aunque fuese necesario rodear muchos lugares para buscar sujetos a su propósito". Aguilar, 1716: 26. 
la observancia" ${ }^{96}$. En el nuevo gobierno trienal de 1698, la mayoría de los rectores y superiores eran novatos. Para compensar su falta de experiencia, el visitador les escribió al año siguiente una carta de instrucción ${ }^{57}$.

Cuadro 6. Allegados identificados de Altamirano (trayectorias ascendientes) ${ }^{58}$.

\begin{tabular}{|l|l|l|l|l|}
\hline & Gobierno Grijalba 1689-91 & Gobierno Eguíluz 1695-97 & Gobierno Alt. 1698-01 & Gobierno Alt. 1702-04 \\
\hline $\begin{array}{l}\text { Fernando de Aguilar } \\
\text { (Castilla) }\end{array}$ & operario La Plata & operario San Pablo & Rector Trujillo & Procurador provincial \\
\hline $\begin{array}{l}\text { Luis de Andrade } \\
\text { (Arica) }\end{array}$ & operario San Pablo & operario San Pablo & teología San Pablo & Rector Cercado \\
\hline $\begin{array}{l}\text { Diego Cárdenas (Nuevo } \\
\text { Reino) }\end{array}$ & teología La Plata & pref. Estudios La Plata & $\begin{array}{l}\text { Rector La Plata/ } \\
\text { canciller Univ. }\end{array}$ & Rector San Pablo \\
\hline $\begin{array}{l}\text { Hernando Colmenero } \\
\text { Lima) }\end{array}$ & confesor Arequipa & Rector Arequipa & Rector Huamanga & Rector Arequipa \\
\hline Manuel Herla (Aragón) & teología San Pablo & Rector colegio San Martin & Rector Cuzco & Consultor provincial \\
\hline Alonso Messia (Lima) & filosofía San Pablo & $\begin{array}{l}\text { operario/pref. Escuela Cristo } \\
\text { San Pablo }\end{array}$ & Rector Cercado & Rector Noviciado \\
\hline $\begin{array}{l}\text { Juan Valdespino } \\
\text { (Lima) }\end{array}$ & operario La Paz & teología San Pablo & $\begin{array}{l}\text { pref. Estudios San } \\
\text { Martin }\end{array}$ & Rector San Martin \\
\hline Luis Villarino (Potosí) & vicerector Potosí & operario/consultor Potosí & Rector Potosí & Rector Potosí \\
\hline $\begin{array}{l}\text { Joaquim de Velasco } \\
\text { (Castilla) }\end{array}$ & operario Noviciado & Rector Callao & Enviado a España \\
\hline
\end{tabular}

Si bien se trató para Altamirano de sanear el funcionamiento de la Provincia, el nuevo gobierno trienal provocó obviamente el rencor de Eguíluz, Yáñez o Tardío. Pese a su política conciliadora, suscitó también la preocupación de sus clientes y allegados quienes se sintieron perjudicados por la mengua de poder de sus patrones. Poco tiempo después de publicarse el nuevo organigrama, empezaron pues a manifestarse las primeras tensiones. A diferencia del conflicto franciscano de 1680, donde se habían enfrentado frailes criollos y peninsulares sobre la cuestión de la alternancia, no se estaba iniciando un conflicto sobre el reparto de poder entre patrias. Se trataba para una facción mixta de defender el poder almacenado durante 15 años a través de prácticas clientelistas. Primero, los jesuitas caídos recurrieron a una estrategia interna. Como Altamirano involuntariamente los conglomeró en el San Pablo, hicieron del colegio su espacio de reacción. Desde allí, apelaron por una parte a Roma para tratar de contrarrestar el visitador. Sin embargo, el General apoyó a su representante y censuró los recursos legales de sus opositores ${ }^{59}$. Por una otra,

56 Ibídem: 24.

57 Altamirano expresó su propósito: "Muéveme, el que la mayor parte de los rectores son de los que nunca han gobernado". Altamirano, 1899: 9.

58 Elaboración propia.

59 En 1701, Eguíluz lamentó que: "muchos debemos recelar de los ymformes, que se hacen, a Nuestro Padre General, por quien esta tan mal informado, y escribe a quien solo quiere conocer lo que le ymforman". Pleito fiscal 
enfrentaron directamente a Altamirano. Como respuesta, el visitador usó sus prerrogativas legales. Quitó a Eguíluz su cargo de consultor por "[expresarse] con alguna falta de moderación" ${ }^{60}$. Asimismo, en diciembre de 1699, Altamirano produjo unos cuadernos de evaluación negativos para la facción (véase cuadro 7).

Cuadro 7. Calificaciones comparadas entre 1696 y 1703 (inversión de tendencias) ${ }^{61}$.

\begin{tabular}{|c|c|c|c|}
\hline & Gobierno Eguiluz & Gobierno Altamirano (diciembre 1699) & Gobierno Eguiluz (enero 1703) \\
\hline \multicolumn{4}{|c|}{ Faccion de Jauregui } \\
\hline José de Aguilar & grande, muy bueno, grande, bastante, cat/letras/pul. & optimum, sufficiens, sufficiens, exigua, mediocre & prestans, bonum, exigua, nulla, bonum \\
\hline Diego de Eguiluz & (Provincial) & $\begin{array}{l}\text { magnum, bonum, mediocre, diturna, consumpta, } \\
\text { preferi aim peditusi }\end{array}$ & bonum, mediocre, exigua, longa, mediocre \\
\hline FX Grijalba & bueno, bueno, buena, mucha, letras & bonum, bonum, mediocris, magna, sufficiens & mediocre, exigum, parva, longa, exiguum \\
\hline Martin de Jauregui & $\begin{array}{l}\text { grandísimo, muy grande, muy grande, muy grande, } \\
\text { catletras }\end{array}$ & $\begin{array}{l}\text { magnum, bonum sed iam fere caducum, attenuata, } \\
\text { diuturna, iam obrutumo }\end{array}$ & optimum, bonum, iam ?, magna, bonum sed consumptum \\
\hline Bartolome de Larrea & grande, bueno, buena, bastante, cat/letras & bonum, bonum, bona, aliqualis, sufficiens & bonum, vividu?, huius mundi, exigua/cogitabusda, mediocre \\
\hline Mateo de Orellana & bueno, bueno, buena, bastante, letras & sufficiens, mediocre, mediocris, exigua, mediocre & sufficiens, sufficiens, mediocris, exigua, exiguum \\
\hline Juan de Orena & bueno, bueno, buena, bastante, pul/letras & bonum, sufficiens, mediocris, mediocris, bonum & sufficiens, sufficiens, mediocris, exigua, sufficienes \\
\hline Nicolas de Torres & suficiente, bueno, bastante, bastante, pul/letras & bonum, bonum, bona, aliqualis, bonum & sufficiens, bonum, mediocris, exigua, mediocre \\
\hline Juan de Yanez & grande, muy grande, muy grande, muy grande, letras & bonum, bonum, bona, sufficiens, mediocre & sufficiens, sufficiens, mediocris, mediocris, mediocre \\
\hline \multicolumn{4}{|c|}{ Allegados de Altamirano } \\
\hline Fernando de Aguilar & grande, suficiente, bastante, bastante, cat/letras/pul. & bonum, optimum, preclara, sufficiens, prestans & bonum, bonum, sufficiens, sufficiens, bonum \\
\hline Luis de Andrade & grande, bueno, buena, bastante, cat/letras/pul. & optimum, bonum, multa, aliqualis, magnum & excelens, bonum, magna, sufficiens, optimum \\
\hline Diego de Cardenas & grande, bueno, buena, bastante, cat/letras/pul. & magnum, bonum, magna, suffuciens, optimum & eximium, ingens, prestans, multa, precellens \\
\hline Hernando Colmenero & bueno, bueno, grande, bastante, cat/letras/pul. & prestans, optimum, magna, diuturna, optimum & bonum, bonum, magna, diuturna, bonum \\
\hline Manuel de Herla & grande, bueno, buena, buena cat/letras/pul. & prestans, optimum, magna, multa, optimum & prestans, optimum, magna, multa, magnum \\
\hline Alonso de Messia & grande, muy bueno, grande, bastante, cat/letras/pul. & magnum, excellens, preclara, sufficiens, prelaclarum & optimum, egregium, magna, sufficiens, magnum \\
\hline Juan de Valdespino & bueno, bueno, bastante, suficiente cat/letras/pul. & magnum, bonum, sufficiens, suffciens, bonum & optimum, ingens, magna, mediocris, bonum \\
\hline Joaquim de Velasco & bueno, buena, buena, bastante, pul/letras & preclarum, bonum, bona, mediocris, optimum & prestans, optimum, excelens, suffcienes, optimum \\
\hline
\end{tabular}

Ante su falta de éxito, el grupo de Eguíluz elaboró luego un contraataque de naturaleza externa, el cual se convirtió en su estrategia central. Contra el visitador y sus poderes extraordinarios, el arequipeño y los suyos movilizaron su principal activo: la fuerza de sus recursos en la capital. Lo que solo había sido una nebulosa transversal, sin propósito común, se convirtió en un verdadero partido con un objetivo definido: debilitar al hombre de Roma. Entre 1700 y 1701, los jesuitas caídos llevaron tres grandes ofensivas contra el Provincial-visitador, respaldados activamente por sus aliados externos, peninsulares como criollos: el virrey Monclova, algunos miembros de la Real Audiencia y del arzobispado, así como por los dos inquisidores limeños. De ahora en adelante, el conflicto se basó en la oposición entre dos tipos de capitales: un capital institucional (grupo de Altamirano) y un capital social (grupo de Eguíluz).

La primera ofensiva se dio a comienzo de 1700. Desde el 2 de noviembre de 1699, Altamirano no se encontraba más en Lima por haber salido a inspeccionar los demás establecimientos de la Provincia. Su ausencia generó rápidamente en la capital un vacío de poder y un momento de oportunidad para sus adversarios, quienes lo aprovecharon rápidamente para intrigar en su contra con el virrey sobre la cuestión del Colegio Real de San Martín. Fundado en 1582 bajo patronato real, el establecimiento ignaciano se benefició en sus inicios de becas financiadas por la Corona. No obstante, durante el siglo siguiente, las becas menguaron y las autoridades jesuitas acompañaron, desde 1657, la disminución de la presencia regia con un abandono de la enseñanza del derecho secular en beneficio exclusivo de los artes y de

del Real Fisco del Tribunal de la Inquisición de Lima con Diego Francisco Altamirano. Madrid, 1701. AHN, Inquisición, 4786, Exp. 3, f. 55r.

60 Vargas Ugarte, 1963, t. II: 323.

${ }^{61}$ Elaboración propia en base a los cuadernos secretos trienales, ARSI, Perú 6. Las calificaciones corresponden a Ingenio, Juicio, Prudencia, Experiencia, Talento. 
la teología ${ }^{62}$. Antes de irse, Altamirano dejó instrucciones que reafirmaban aquellas directivas romanas: "no [se] introduzga en Sn Martín, admita ni permita entrar para Colegial de Beca dotada, o no dotada a alguno que no sea para cursar y estudiar Artes y theologia puramente y no derechos"63. Para el visitador, se trató entonces de una banal revalidación de disposiciones antiguas, en el marco de una situación de más de cuarenta años. Sin embargo, para sus adversarios en la Provincia, estas instrucciones firmadas por él constituyeron un pretexto eficiente para, con el apoyo de su aliado Monclova, vulnerar su autoridad.

Oriundo de Madrid, el Conde de la Monclova dirigía el Virreinato desde 1689. Tanto él como diferentes miembros de su séquito (su médico Centellas o uno de sus gentilhombres, el cántabro Alvarado) mantenían, desde hacía varios años ya, estrechas relaciones con integrantes de la facción jesuita caída (véase cuadro 5). A comienzo del mes de marzo, juntos conspiraron para invalidar las instrucciones del visitador ausente respecto al Colegio. El 6 de marzo, el virrey proporcionó a Eguíluz, Yáñez y Grijalba, durante una "conversación privada", una contraorden, con la cual se exigía la reapertura del San Martín para los becados y la reanudación de las clases de derecho secular ${ }^{64}$. Al día siguiente, los jesuitas instrumentalizaron la Consulta que seguían controlando para pasar a la fuerza. Primero, Yáñez y Grijalba pidieron una reunión inopinada de la asamblea para tratar del asunto. Luego, con la excusa de la negativa de Monclova de esperar a que Altamirano fuese informado, la elevaron a una posición de autoridad sustitutiva, en contradicción con los estatutos de la Compañía ${ }^{65}$. Obviamente, la deliberación de los consultores los llevó a satisfacer las exigencias de su aliado Monclova, en contra de las indicaciones explícitas de Altamirano ${ }^{66}$. Para el visitador, constituyó una doble vulneración a su prestigio. En la Provincia y ante sus integrantes, sus adversarios y el virrey socavaban su poder. En la capital y en la Corte, desacreditaban su autoridad. De hecho, una vez informado, el visitador se dedicó a tratar de invalidar la medida tomada por los consultores a sus espaldas ${ }^{67}$.

La segunda ofensiva en contra de Altamirano tuvo lugar cuatro meses después, a finales de junio de 1700. Por entonces, el visitador seguía en Cuzco y el procedimiento empleado en su contra fue similar al precedente. De nuevo, sus adversarios aprovecharon su ausencia en Lima para instrumentalizar en contra suya instrucciones brindadas antes de su salida, las cuales correspondían no obstante otra vez a direc-

62 En la misma Provincia peruana, esa política educativa ya había ocasionado en 1681 un conflicto en La Plata entre el colegio jesuita y la Real Audiencia. Vargas Ugarte, 1963, t. II: 231. Para la cronología y las razones específicas del abandono de la enseñanza del derecho secular en el San Martín, véase: Carta de Altamirano al virrey Monclova. Lima, II-X-1701. CVU, T. 14, doc. 50, f. 3r.

63 Consulta extraordinaria de la Consulta. Lima, 23-III-1701. CVU, T. 14, doc. 47, f. 2r.

${ }_{64}$ Grijalba y Yáñez explicaron el día siguiente a la Consulta que el Virrey los llamó: "para en conversación privada hacerles saber tenía en su mano su Exa un decreto del Real acuerdo por voto consultivo [...] en que se manda, lo primero que su Exa como Patrón mantuviese el derecho de nombrar quatro becas en San Martín [...]. Lo segundo que pudiesen estudiar libremente la facultad de leyes, en dicho colegio, todos los Colegiales". Consulta extraordinaria de la Consulta. Lima, 23-III-1701. CVU, T. 14, doc. 47, f. 1r. Sobre la presencia de Eguíluz en Palacio: "en la consulta refirió el Pe Diego de Eguíluz, de averle prevenido su Exa por recaudo". Ibídem: f. 4r.

65 "Suplicaron [Yáñez y Grijalba] no se entregará el Decreto hasta tanto que se diere noticia del a su Padre visitador, porque en Lima no avia quien fuese [¿?], para poder legítimamente responder; [Monclova] cerró también la puerta a esa súplica, diciendo no daría esa espera". Ibídem.

${ }_{66}$ Los consultores indicaron al rector del San Martín contestar que: "no era parte formal para responder, y que aunque no lo era, obedecía en quanto podía al decreto de su Exa". Ibídem, f. 11r.

67 Carta de Altamirano al virrey Monclova. Lima, II-X-1701. CVU, T. 14, doc. 50; Razón sobre becas del Colegio de San Martín. Potosí, 1-XI-1706. CVU, T. 14, doc. 51. 
tivas antiguas. Las complicidades externas fueron en cambio diferentes. Si bien en marzo el partido de Eguíluz se apoyó sobre sus conexiones cortesanas, recurrieron esta vez a los inquisidores. Gracias a los hermanos Larrea, estaban particularmente cercanos al Inquisidor Valera, originario de Lima. Desde el San Pablo, acordaron con él utilizar el tribunal para perjudicar la autoridad del visitador ${ }^{68}$. El plan fue simple. Se trató de someter una propuesta de Altamirano al Santo Oficio, cuyos funcionarios se encargarían luego de condenarla gracias a dos transgresiones al proceso legal: la omisión de la defensa y calificadores parciales ${ }^{69}$.

Cuadro 8. Repartición de los altos cargos de la Provincia entre 1698 y 1709 (renovación alta) ${ }^{70}$.

\begin{tabular}{|l|l|l|l|}
\hline \multicolumn{1}{|c|}{ Trienios } & \multicolumn{1}{|c|}{ 1698-1701 } & \multicolumn{1}{c|}{$1702-1705$} & \multicolumn{1}{c|}{ 1706-1709 } \\
\hline Provincial & Altamirano & Altamirano & Diego de Cárdenas \\
\hline \multicolumn{5}{|c|}{ Principales colegios de Lima } \\
\hline Rector San Pablo & FX Grijalba (castilla) & Diego de Cárdenas & Altamirano \\
\hline Rector noviciado & Nicolás de Olea & Alonso Messia & Miguel de Oña \\
\hline Rector Cercado & Alonso Messia & Luis de Andrade & FX Grijalba \\
\hline \multicolumn{5}{|c|}{ Consulta de la Provincia } \\
\hline Consultores & $\begin{array}{l}\text { FX Grijalba } \\
\text { F Tardío } \\
\text { Nicolás de Olea } \\
\text { Martín Jáuregui }\end{array}$ & $\begin{array}{l}\text { Diego de Cárdenas } \\
\text { Alonso Messia } \\
\text { Luis de Andrade }\end{array}$ & $\begin{array}{l}\text { Altamirano } \\
\text { Cespedes } \\
\text { J Yanez } \\
\text { Miguel de Ona }\end{array}$ \\
\hline
\end{tabular}

En ese sentido, el 26 de junio, un cliente de la facción caída, Francisco Xavier Salduendo, fue enviado al Santo Oficio por su superior en el San Pablo, el rector Grijalba, para declinar un cargo de calificador que le acabada de ser atribuido. A manera de explicación, el jesuita afirmó conformarse con las órdenes de Altamirano que prohibían a los miembros de la Provincia aceptar el cargo de calificador sin su acuerdo previo ${ }^{71}$. Como en el caso de San Martín, la prohibición se derivaba de políticas antiguas en la Provincia y era compartida incluso por una Orden como la franciscana ${ }^{72}$. Tal como lo explicaría el visitador, se originaba en una necesaria re-

68 Para un análisis del episodio como simple conflicto corporativo: Guibovich, 2003: 78-80.

69 Altamirano lo subrayaría: "las circunstancias de darme esta sentencia [el auto], sin aver hecho juicio conmigo, ni averme citado, ni hecho cargo, ni averme convencido de delito alguno". Carta de Altamirano a los Inquisidores del Tribunal de Lima. Lima, 1702. CVU, T. 40, doc. 10, f. 1v. Su representante en Madrid también: Pleito fiscal del Real Fisco del Tribunal de la Inquisición de Lima con Diego Francisco Altamirano. Madrid, 1701. AHN, Inquisición 4786, Exp. 3, f. 424.

70 Elaboración propia.

71 "Ordenasse a todos los nuestros con todo aprieto, que ninguno admita el officio de calificador del santo oficio sin aguardar primero la licencia del Provincial”. Ibídem, f. 4r.

72 Desde hacía varias décadas, las instancias romanas limitaban a 6 el número de calificadores para la Provincia. Para los franciscanos, el 23 de mayo de 1701, el comisario general Miguel de Mora reconoció clausulas similares en la Provincia franciscano. Ibídem: f. 35v. 
gulación de los honores ${ }^{73}$. Como bien lo sabían Grijalba y los inquisidores, bastaba no obstante para alegar una vulneración de las prerrogativas del Santo Oficio. En efecto, Valera abrió en el acto una investigación. Luego, para garantizar su resultado, infringió a los derechos de la defensa ${ }^{74}$. Los Inquisidores recibieron como testigo a Grijalba para que confirmase la directiva de Altamirano, pero no quisieron escuchar los argumentos del visitador. El 28 de junio, rechazaron a unos de sus lugartenientes, Luis de Andrade, que se presentó al tribunal en nombre de su jefe ${ }^{75}$. Sobre todo, los Inquisidores designaron como calificadores de la causa a individuos cercanos, de manera notoria, al grupo de Eguíluz: los franciscanos Gregorio de Quesada y Ignacio del Campo (véase cuadro 5). De hecho, los dos calificadores condenaron obviamente la prohibición de Altamirano e impulsaron, en septiembre, a que los inquisidores Valera y Suárez lo amonestaran por vía epistolar.

La carta llegó por el mes de octubre al visitador, quien por entonces ya debía de estar informado de lo que se tramaba por sus hombres de confianza en Lima. Probablemente consciente de la trampa que se le tendía, Altamirano apostó por el apaciguamiento. El 1. ${ }^{\circ}$ de noviembre, escribió a los Inquisidores que se conformaba con su dictamen y con la suspensión de la prohibición ${ }^{76}$. El 18 de enero de 1701, su respuesta fue leída en el Tribunal inquisitorial capitalino. Obviamente, los Inquisidores no se complacieron con una benévola contrición. Primero, para reactivar el caso, sometieron la respuesta del visitador a un nuevo examen. Segundo, para asegurar la acusación, llamaron nuevamente a calificadores parciales. Pidieron otra vez las calificaciones de Quesada y de Campos. Pero, sobre todo, no dudaron ya en solicitar directamente las calificaciones de dos enemigos jesuitas de Altamirano: el propio Eguíluz y un allegado suyo, José de Aguilar ${ }^{77}$.

Realizadas por sus adversarios, las diferentes calificaciones resultaron muy duras para el visitador. E1 25 de enero, Quesada señaló que Altamirano "muestra un ánimo libre de censura theologica y criminal, por ser las razones que manifiesta nacidas de ignorancia o de una inadvertencia poco prevenida a las consecuencias, que de semejante mandato se podían seguir contra la autoridad de este santo tribunal"78. Ese mismo día, Eguíluz y Aguilar escribieron que "la erudición con que gasta el P Visitador [para justificar haber dado su directiva] tiene [...] tantas disparidades, que no

73 "Juzgue muy de mi obligación el aplicar algún medio para impedir ambición y pretenciones ilícitas en los súbditos". Ibídem: f. 41r. Para 1700, eran 22 calificadores en total en la Provincia y 14 en Lima, pese a la limitación romana. Ibídem.

74 Sobre la defensa, según Altamirano: "De donde noto q de ningún modo se me permite mi defensa, ni por mí, pues no se me hace cargo, ni por un súbdito mío". Carta de Altamirano a los Inquisidores del Tribunal de Lima. Lima, 1702. CVU, T. 40, doc. 10,f.4r.

75 "Luis de Andrade, sugeto mozo y no de muy asentado juicio por haber salido a la defensa de su orden con tanta intrepidez como desacato. Pleito fiscal del Real Fisco del Tribunal de la Inquisición de Lima con Diego Francisco Altamirano. Madrid, 1701. AHN, Inquisición 4786, Exp. 3, f. 2 v.

76 "Pero algo a herrado mi cortedad, muy pronto estoy [tachado] corrección y enmienda, como a ejecutar con muy rendida y presta obediencia quanto se sirviese mandarme el santo tribunal”. Ibídem: f. 41r.

77 Los Inquisidores justificaron su elección alegando el conocimiento necesario de la Compañía: "en consideración con la gravedad de esta materia, y para asegurar el acierto en su resolución, parece conveniente oyr a Religiosos de la misma Compañía de secreto, letras y juicio y desinterés y con inteligencia en las leyes municipales de su Religión, se dara también este ymforme para que lo califiquen". Ibídem, f. 43r. Para tratar de esconder luego a la Suprema en Madrid este manejo parcial, las calificaciones de Eguíluz y de Aguilar fueron colocadas al final de las calificaciones, pese a estar fechadas anteriormente.

78 Ibídem: f. 44r. 
sirven al caso" 79 . Por lo tanto, el 28 de enero, los Inquisidores pidieron oficialmente a Altamirano que borrase su directiva delante de todo el colegio de San Pablo. El 6 de abril, exigieron además la presencia de los rectores de los otros colegios limeños.

Para el visitador ausente, se trató de un nuevo desaire ${ }^{80}$. Si bien acató en apariencia la sentencia del Santo Oficio, Altamirano empezó a reaccionar a nivel interno con su principal arma: sus poderes extraordinarios. Se centró en particular sobre el instigador visible de su problema con la Inquisición y uno de los últimos miembros de la facción caída aún en el poder: Grijalba. Desde el Cuzco, ordenó al castellano que se reuniese con él y dejase el rectorado del San Pablo a su protegido Luis de Andrade. Sin embargo, el partido de Grijalba se activó inmediatamente en Lima para evitar su salida. Los jesuitas recurrieron otra vez a sus relaciones fuera de la Compañía. A mediados de abril, desencadenaron su tercera ofensiva en contra de Altamirano, la cual se fundamentó sobre una movilización más amplia de su red de aliados en la capital. Esta vez, los dos inquisidores, el virrey y varios miembros de la Audiencia, así como diversas personalidades del Arzobispado, participaron en la intriga.

Entre el 15 y el 28 de abril de 1701, diferentes miembros del partido jesuita se presentaron, uno tras otro, en el Santo Oficio para señalar el traslado de Grijalba como una nueva vulneración al Tribunal. El procedimiento fue similar al anterior. Tal como lo señalaría un seguidor del visitador, se trataba de "impedir los mandatos de los Superiores [...] con pretexto de mantener la libertad de este santo tribunal" $"$. El primero en comparecer fue Diego de Eguíluz. Durante los días siguientes, lo siguieron sus partidarios José de Aguilar, Fernando de Tardío, Nicolás de Torres, Juan de Oreña y José de Buendía. Ante los Inquisidores, los jesuitas produjeron el mismo argumentario: el traslado de Grijalba era un castigo por haber confirmado la directiva relativa a los calificadores. Su salida era pues otra afrenta a la Inquisición. En paralelo, el grupo de jesuitas solicitó también a sus apoyos en la Corte, como el Conde de la Monclova. Algunos miembros de la Audiencia, en su mayoría peninsulares, como el Oidor jubilado Diego Messia, amigo de Tardío y primo de Aguilar, o el fiscal Pedro Vasquez de Velasco, amigo también de Aguilar, se pronunciaron a favor de Grijalba en base al mismo argumento ${ }^{82}$. A nivel del arzobispado, un amigo de Buendía, el Dr. Francisco Carrasco Orozco, se desplazó incluso físicamente a la Inquisición para respaldar a sus aliados jesuitas. Obviamente, los dos Inquisidores no consultaron nuevamente a la parte opuesta ${ }^{83}$. Sin escucharla, el 4 de mayo de 1701, publicaron un auto que prohibía a Altamirano separar a Grijalba del San Pablo hasta el final del trienio.

Para el visitador, el auto del Santo Oficio constituyó una tercera derrota consecutiva. El representante ignaciano en la Corte madrileña, Juan Martínez de Ripalda, señalaría en 1706, cómo, con el auto, "se abría puerta tan franca a la relajación de los súbditos, quedando tan desauthorizada la potestad de los superiores" ${ }^{" 84}$. Sin embargo,

79 Ibídem: f. 52v.

${ }^{80}$ Un partidario del visitador, Joaquín Velasco, señaló el objetivo de la Inquisición: “desautorizar la persona y fama de un hombre tan venerable por sus virtudes [...]". Ibídem: f. 419.

81 Pleito fiscal del Real Fisco del Tribunal de la Inquisición de Lima con Diego Francisco Altamirano. Madrid, 1701. AHN, Inquisición 4786, Exp. 3, f. 112r.

82 Ibídem: f. 66r y ss.

83 Los apoyos de Altamirano se lo reprocharon también luego. Ibídem: f. 13v.

${ }_{84}$ Ibídem: f. 9v. El 18 de junio de 1701, Fernando de Aguilar, procurador de Provincia y partidario de Altamirano, senaloo por su parte a los inquisidores: "tiene gravísimo inconveniente [el auto], y casso que corriese a la vista de toda la Provincia se perburbara su quietud su obediencia su mayor perfección”. Ibídem: f. 109r. 
Altamirano no carecía de recursos. Frente a la última embestida de sus adversarios y de sus aliados externos, recurrió otra vez a su capital institucional. Si bien el intervalo entre marzo de 1700 y mayo de 1701 no le fue favorable, para noviembre de 1701, Altamirano tenía retomado el control de la Provincia y neutralizado a sus enemigos gracias, en gran medida, a un nuevo reparto de cargos y ministerios.

\section{Resolución: la victoria del visitador (1702)}

Ante el revés que significó para su autoridad el auto inquisitorial, Altamirano estimó necesario abandonar el Cuzco para regresar en Lima y enfrentarse en persona a la disidencia interna. El visitador no se alojó en el San Pablo por prudencia, sino en el colegio del Cercado, cuyo rector, Alonso de Messia, era un allegado ${ }^{85}$. En un primer momento, trató de negociar con los Inquisidores la suspensión del auto. El 18 de junio de 1701, uno de sus lugartenientes, Fernando de Aguilar, se presentó en este sentido al Santo Oficio, pero sin éxito. Entonces, en un segundo momento, Altamirano empleó sus prerrogativas extraordinarias. Por el mes de septiembre, recurrió a una astucia legal. Nombró a Luis de Andrade visitador del San Pablo. El nombramiento daba legalmente al ariqueño la dirección del colegio sin tocar a su rector, Grijalba, que el auto inquisitorial mantenía en el cargo ${ }^{86}$. Sobre todo, Altamirano preparó en paralelo el organigrama del nuevo trienio que se acercaba. Si bien, en diciembre de 1697, se conformó con una política relativamente diplomática con la facción de Grijalba y Eguíluz, los acontecimientos de 1700 y 1701 lo impulsaron a más severidad. No solo el visitador castigó esta vez a más individuos, sino que también intensificó sus medidas. A través de la retrogradación jerárquica o del traslado geográfico, aceleró el proceso de desarticulación del partido de sus adversarios.

El 25 de noviembre de 1701, Altamirano comunicó a la Provincia la composición del nuevo gobierno trienal. Primero, se ocupó del sector más alto del grupo de Eguíluz y se dedicó a terminar de liquidar su poder y sus márgenes de acción (véase cuadro 4). Por una parte, les quitó a todos sus cargos de consultores de Provincia para arrebatarles el control de la Consulta. Por otra, Altamirano bien los rebajó en la jerarquía interna, bien los alejó de la capital. Individuos como Juan de Yáñez, Diego de Eguíluz y Martín de Jáuregui fueron pasados a retiro ${ }^{87}$, mientras que las posiciones de Olea y Tardío disminuyeron significativamente. Por su parte, Grijalba fue mandado, a manera de exilio punitivo, a visitar los colegios de Huancavelica y $\mathrm{Pisco}^{88}$. Segundo, Altamirano tocó esta vez al nivel intermedio de sus apoyos. Según la misma dinámica de degradación y traslado, relegó a José de Buendía, Bartolomé de Larrea, Francisco Xavier Salduendo o Gerónimo Tello. Al mismo tiempo, envió a Nicolás de Torres y José de Rotalde al Cuzco. En reemplazo, el visitador acentuó el

\footnotetext{
85 Según la carta que presentó el día siguiente Fernando de Aguilar a la Inquisición.

86 "Lo constituyó [a Andrade] visitador de dho colegio todo afín de solo dejar el nombre de rector al Padre Francisco Xavier [de Grijalba]". Pleito fiscal del Real Fisco del Tribunal de la Inquisición de Lima con Diego Francisco Altamirano. Madrid, 1701. AHN, Inquisición 4786, Exp. 3, f. 2v/3e. También: "No es oprimir al Pe Xavier afectar los desayres, las desatenciones y desprecio, no haciendo aprecio del para cosa ninguna de su colegio, [...], dexándole el título de rector, no el exercicio de tal [...]”. Ibídem, f. 138v.

87 Aparecen en el catálogo de 1702 como "valetudinarius".

88 Según la Inquisición en 1701. Para el catálogo de 1702, Grijalba se encontraba nuevamente o aun en el San Pablo como simple operario.
} 
ascenso de los miembros que habían demostrado su lealtad (véanse cuadros 6 y 8). Los cargos de consultores provinciales así como los rectorados de los principales colegios limeños recayeron en sus hombres de confianza, más jóvenes y todos criollos: Luis de Andrade, Diego de Cárdenas y Alonso de Messia.

La dimensión de esa reorganización significó un fuerte reequilibrio de las fuerzas dentro de la Provincia como fuera de ella. Tanto para los jesuitas como en la capital, debió de provocar un choque fuerte, que se vería justificado incluso posteriormente por el biógrafo del visitador en base a un principio meritocrático:

buscaba [Altamirano] sujetos para las ocupaciones, los más adequados que le parecían; y si no satisfacían, no se embarazaba en removerlos, sin empacharse de deshacer lo hecho, ni de revocar aquellos ordenes, que el tiempo y la experiencia mostraban ser menos acertadas, sabiendo, que es gran parte de la prudencia el mudar consejos, quando la nueva luz descubre, o manifesta la verdad ${ }^{89}$.

Los días siguientes a su publicación, los diferentes aliados de los jesuitas caídos trataron de impedir el establecimiento del nuevo gobierno. Informados oficialmente a la mañana siguiente por Grijalba, el 26 de noviembre, los Inquisidores reaccionaron rápidamente. Cuatro días después, el lero de diciembre, terminaron de constituir un expediente contra Altamirano destinado a la Suprema en Madrid ${ }^{90}$. En la esfera cortesana, las diferentes partes entablaron sin duda negociaciones que llevaron a una relativa calma entre Altamirano y Monclova. Por una parte, cuatro meses más tarde, la pareja virreinal se mostró en efecto públicamente durante un sermón del visitador $^{91}$. Por otra, un año después, el 31 de diciembre, Grijalba y Torres permanecían aún en el San Pablo ${ }^{92}$. Para Altamirano, se trató pues de un pequeño gesto con respecto al éxito de su acción, la cual le devolvió provisionalmente un sólido control de la Provincia. A nivel externo, la reorganización trienal neutralizó temporalmente la filtración de intereses exógenos en la institución ${ }^{93}$. A nivel interno, terminó de desplazar a sus adversarios en beneficio de sus seguidores. Por ejemplo, cuando dos de sus allegados como Andrade y Messia subieron en la jerarquía ignaciana en unos pocos años, José de Aguilar vio en cambio su trayectoria estancarse (véase cuadro 9).

89 Aguilar, 1716: 22-23.

90 "Dicho Padre Visitador nos ha faltado a todos en términos de atención, cortesía y aun propasándose a vulnerar los fueros más sagrados del tribunal". Carta de los Inquisidores del 2 de diciembre para la Suprema. Pleito fiscal del Real Fisco del Tribunal de la Inquisición de Lima con Diego Francisco Altamirano. Madrid, 1701. AHN, Inquisición 4786, Exp. 3, f. 1r. El procedimiento no tendrá éxito.

91 "Asistieron [...] Sus Excelencias; predicó el reverendísimo padre Diego Francisco Altamirano, visitador de la Compañía en esta provincia del Perú, del patrocinio del santo apóstol para con sus devotos, afervorizando el concurso en su devoción y confianza, de que quedó Su Excelencia muy gustoso, y todo el crecido auditorio muy contento". Firbas, 2017: 147.

92 Según el catálogo de 1702, firmado por Altamirano el 31 de diciembre de 1702. Ambos son registrados como simples operarios.

93 Pese a la degradación del grupo de Eguíluz, sus aliados en la Corte o en la Real Audiencia mantuvieron un fuerte lazo. Véase la muerte del arequipeño, por ejemplo: "El concurso a su entierro [de Eguíluz] fue de los mayores que ha visto esta ciudad, asistiendo Su Excelencia, Real Audiencia y todos los tribunales con los prelados de las religiones, y toda la nobleza de esta ciudad con capas largas, que convidó el señor general don Antonio Portocarrero, y celebrando sus exequias, el venerable deán y Cabildo Eclesiástico". Ibídem: 325. También tanto Monclova como la Audiencia siguieron empleando como oradores figuras como Orellana, Buendía y Aguilar. Ibídem: 281 y 327. 
Cuadro 9. Trayectorias comparadas entre jesuitas criollos de ambos bandos (inversión de tendencias) ${ }^{94}$.

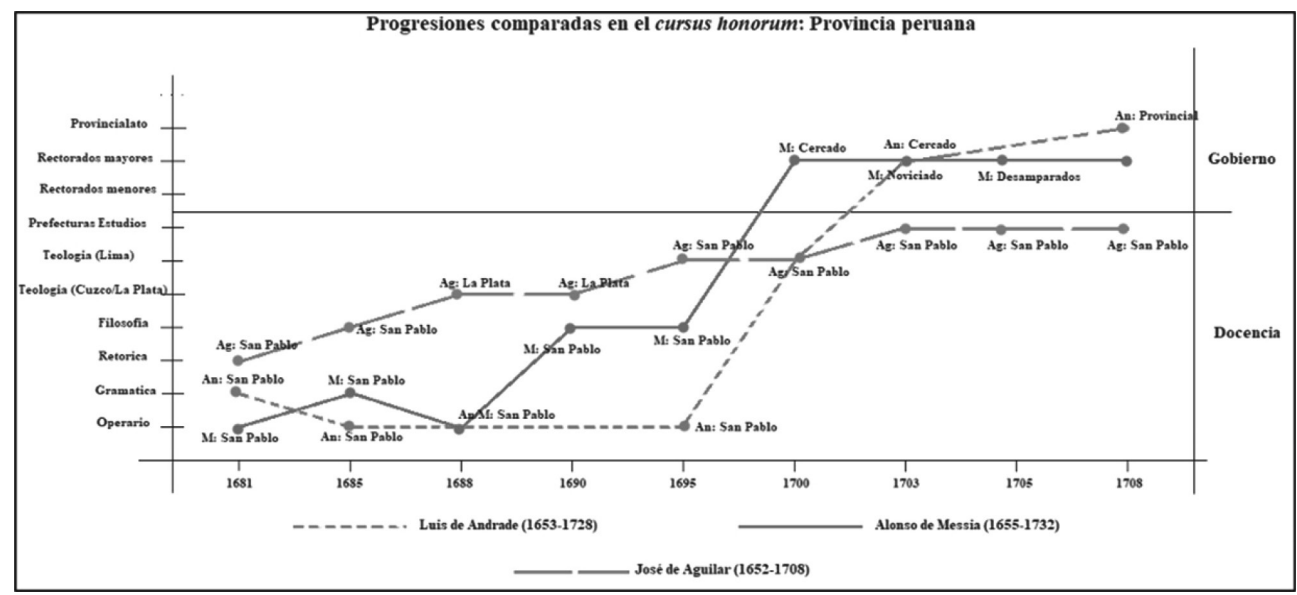

\section{Conclusión}

A finales de 1705, la visita de la Provincia peruana fue oficialmente dada por concluida por las instancias romanas que recuperaron sus prerrogativas. Para el trienio 1706-1709, fueron ellas quienes se encargaron del reparto de los cargos executivos. En Roma, el contexto era entonces menos favorable para Altamirano con un Tirso de González disminuido ${ }^{95}$. En vez de seguir apoyándolo sin restricciones, las autoridades ignacianas escogieron optar por la reconciliación. En el nuevo organigrama directivo, reintegraron algunas figuras de la facción caída. Cargos de consultores provinciales fueron restituidos a Urbano de Céspedes o a Juan de Yáñez. En términos de rectorados, Bartolomé de Larrea obtuvo el San Martín y a Grijalba se le atribuyó la dirección del Colegio del Cercado. Para ellos, se trató pues de un consuelo luego de tres años en la sombra. Sin embargo, el ganador siguió siendo Altamirano. El jesuita conservó una posición poderosa. Recibió el rectorado del San Pablo, que lo elevaba también a la consultoría de Provincia. Sobre todo, sus protegidos estaban ya sólidamente incorporados al aparato gubernamental. Además de rectorados y consultorías para sus hombres de confianza, allegados como los criollos Cárdenas, Andrade y Messia le sucedieron al Provincialato hasta 1715.

Este texto no tiene la pretensión de haberlo dicho todo sobre el conflicto tratado. A nivel de los actores, varias figuras no han sido mencionadas por cuestión de espacio, a pesar de su protagonismo (los jesuitas Mateo de Orellana y Joaquín de Velasco por ejemplo). A nivel del análisis, numerosos aspectos han sido dejados de lado, pese a su interés, como el uso de los cuadernos secretos de evaluación o la instrumentalización de la opinión pública. Sin embargo, dos elementos pueden subrayarse, de

94 Elaboración propia. Entre 1706 y 1708, Andrade fue Provincial de la Provincia del Nuevo Reino. Para llegar a las cátedras de teología del San Pablo, los docentes tenían que ejercer primero en La Plata o el Cuzco. Vargas Ugarte, 1963, t. II: 309.

95 Tirso de González falleció el 27 de octubre de 1705. Debido a la distancia, la composición del gobierno de la Provincia debió de decidirse no obstante antes de su muerte. 
orden metodológico e historiográfico. En términos metodológicos, se trata de recalcar el interés para la investigación de instrumentos procedentes de la sociología de las organizaciones o del análisis de redes. Al interesarse a los mecanismos internos de distribución de los recursos, ya sean formales o informales, la primera facilita la identificación de los potenciales puntos de fricción entre miembros. Por su parte, el análisis de redes proporciona valiosos indicios sobre las modalidades del arraigo social de los miembros de la Provincia, tanto dentro como fuera de ella. En este caso, señala la diversidad de intereses y la amplitud elevada de las sociabilidades ignacianas.

En términos de historiografía, este artículo muestra la inoperancia de una lectura binaria tradicional, de criollos versus peninsulares, para entender la naturaleza del conflicto que sacudió la Provincia peruana en el periodo de final del siglo XVII. A diferencia de otros enfrentamientos conventuales, el conflicto que dividió a la Provincia jesuita no nació pues de rivalidades patrióticas. Surgió del monopolio de recursos internos por un grupo faccionario y clientelista, ampliamente transversal, en el que las patrias tenían poca importancia en comparación con las posiciones o alianzas de cada uno dentro de la institución como de la sociedad virreinal. Guiado por una lógica de influencia, este grupo chocó con la lógica institucional del visitador, quien supo apoyarse sobre los descontentos y marginados en la Provincia para arrebatarle el poder. O sea, el conflicto resultó de la oposición fundamental entre una facción jesuita, poderosamente conectada con los más altos sectores del virreinato (Corte, Audiencia, Inquisición...) gracias en gran medida a prácticas clientelistas, y un grupo liderado por el representante del General y su política de saneamiento de la Provincia. En ese sentido, si bien la Provincia conoció anteriormente manifestaciones criollistas, para finales del siglo, los dos lados en pugna eran compuestos indistintamente por criollos como por peninsulares.

De hecho, esta heterogeneidad patriótica coincide con el de otros sectores de las sociedades indianas, tal como ya lo han señalado varios estudios ${ }^{96}$. Pero conduce no obstante a más interrogantes. La relevancia menor de los patriotismos en la Provincia ¿fue específico a las últimas décadas del siglo XVII? ¿Y cuándo y por qué aminoraron? Asimismo, ¿ese papel menor se debió a tener la Provincia su centro en Lima, ciudad burocrática y cortesana en la que llegaban regularmente además nuevas élites, procedentes de todo el Imperio? ¿O, al contrario, la situación de la Provincia peruana puede observarse en otras jurisdicciones regulares en los territorios americanos del Imperio hispánico? O sea, ¿existe una repartición diferenciada de la intensidad de los patriotismos en Indias?

\section{Referencias bibliográficas}

Acosta, Antonio. "Sobre criollismo y criollos". Revista Andina, $\mathrm{n}^{\circ} 1$ (1984), 73-88.

Aguilar, Fernando. Carta del Padre Fernando de Aguilar, de la Compañia de Jesús, Rector del Colegio Máximo de San Pablo de Lima para los superiores de las casas y colegios de esta Provincia del Perú, sobre la muerte y vida exemplar del Padre Diego Francisco Altamirano, sugeto, y visitador, que fue de esta misma provincia. [s.n.], 1716.

96 Bertrand, 1999; Huerta, 1997; Lohmann, 1974; Pérez Vejo, 2010; Rosenmuller, 2008. 
Altamirano, Diego Francisco. Carta a los padres y hermanos de la provincia del Perú sobre la manera de gobernar. Buenos Aires: Coni Hermanos, 1899.

Arrom, Juan José. "Criollo: definición y matices de un concepto". Hispania, n 34 (1951), 172-176.

Bertrand, Michel. Grandeur et misères de l'Office : les officiers de finances de NouvelleEspagne (XVIIe-XVIIIe siècles). París: PUS, 1999.

Borja Medina, Francisco. "Métodos misionales de la Compañía de Jesús en América Hispana y Filipinas". Revista del humanismo español e iberoamericano, n4 (1999), 159-192.

Cañeque, Alejandro. "De parientes, criados y gracias: Cultura del don y poder en el México colonial (siglos XVI-XVII)". Histórica, Vol. 29, nº 1 (2005), 3-42

Coello de la Rosa, Alexandro. "De mestizos y criollos en la Compañía de Jesús (Perú, siglos XVI-XVII)”. Revista de Indias, vol. LXVIII, nº 243 (2008), 37-66.

Demoustier, Adrien. "La distinction des fonctions et l'exercice du pouvoir selon les règles de la Compagnie de Jésus". En Jésuites à la Renaissance : système éducatif et production du savoir, editado por Luce Giard. Paris: PUF, 1995.

Estenssoro, Juan Carlos. Del paganismo a la santidad: La incorporación de los indios del Perú al catolicismo, 1532-1750. Lima: IFEA, 2003.

Firbas, Paul. Diario de noticias sobresalientes en Lima y noticias de Europa. New York: IDEA, 2017.

Frost, Elsa Cecilia. Franciscanos y mundo religioso en México. México: Unam, 1993.

Gato Castaño, Purificación. "Tensiones eclesiásticas entre criollos y peninsulares en la Audiencia de Charcas en el último tercio del siglo XVIII". Hispana Sacra, n 40 (1988), 763-776.

Guibovich, Pedro. Censura, libros e inquisición en el Perú colonial, 1570-1754. Madrid: CSIC, 2003.

Huerta, María Teresa. "Los Retes: prototipo del mercader de plata novohispano en la segunda mitad del siglo XVII". En Los vascos en las regiones de México, vol. III, coordinado por Amaya Garritz. México: UNAM, 1997, 71-85.

Ibarra, Antonio. Redes sociales e instituciones comerciales en el imperio español. México: UNAM, 2007.

Jouanen, José. Historia de la Compañia de Jesús en la antigua provincia de Quito, 15701774. Quito: Editorial Ecuatoriana, 1943.

Laske, Trilce. "Cursus honorum y consagración profana: dos letrados jesuitas en Lima, José de Aguilar (1652-1707) y José de Buendía (1644-1727)”. Cuadernos de Historia, no 51 (2019), 85-123.

Lavallé, Bernard. Recherches sur l'apparition de la conscience créole dans la vice-royauté du Pérou, l'antagonisme hispano-créole dans les ordres religieux (XVI ${ }^{\circ}$-XVII ${ }^{\circ}$ siècle). Lille: ANRT, 1982.

- Las promesas ambiguas, ensayos sobre el criollismo colonial en los Andes. Lima: PUCPInstituto Riva Agüero, 1993.

Lohman Villena, Guillermo. Los ministros de la Audiencia de Lima en el reinado de los Borbones 1700-1821. Sevilla: Escuela de Estudios Hispano-Americanos, 1974.

Lukács, Ladislaus. Catalogi personarum et officiorum Provinciae Austriae S.I. 1684-1699, tomo V. Roma: Institutum historicum S.I, 1990.

Maldavsky, Aliocha. Vocaciones inciertas: misión y misioneros en la provincia jesuita del Perù en los siglos XVI y XVII. Madrid: CSIC, 2012.

Mugaburu, José. Diario de Lima: 1640-1694, tomo II. Lima: SanMartí y Ca, 1918.

Pérez Vejo, Tomas. "Criollos contra peninsulares: la bella leyenda". Les Cahiers ALHIM, $\mathrm{n}^{\circ} 19(2010)$. 
Revuelta, Manuel. Los colegios de jesuitas y su tradición educativa (1868-1906). Madrid: Universidad Pontificia Comillas, 1998.

Rosenmuller, Christophe. Patrons, partisans, and palace intrigues: the court society of colonial Mexico, 1702-1710. Algary: University of Calgary Press, 2008.

Rubial García, Antonio. Una monarquía criolla. La provincia agustina de México en el siglo XVII. México: Conaculta, 1990.

Philippart, Guy. "Visiteurs, commissaires et inspecteurs de la Compagnie de Jésus, 15401615”. Archiviom Historicum Societatis Iesu, n³7 (1968), 170-229.

Saldamando, Enrique. Los Antiguos jesuitas del Perú, biografías y apuntes para su historia. Lima: Imp. Liberal, 1882.

Serrano Rodríguez. Toledo y los Dominicos en la época medieval: Instituciones, economía, sociedad. Cuenca: Universidad de Castilla-La Mancha, 2014.

Sato, Masaki. "Revisando a criollos y al criollismo en el virreinato peruano del siglo XVII: el caso de Fray Buenaventura de Salinas y Córdoba". Historia y Cultura, n 27 (2014), 83-117.

Torre Curiel, José Refugio. Vicarios en entredicho: crisis y desestructuración de la provincia franciscana de Santiago de Xalisco, 1749-1860. México: El Colegio de Michoacán, 2001.

Vargas Ugarte, Rubén. Historia de la Compañía de Jesús en el Perú, tomo II. Burgos: Impr. de Aldecoa, 1963.

Yun Casalilla, Bartolomé. Las redes del imperio: élites sociales en la articulación de la Monarquía Hispánica. Madrid: Pons, 2009.

\section{Anexos}

Árbol genealógico tentativo: Nicolás de Olea y su entorno familiar ${ }^{97}$.

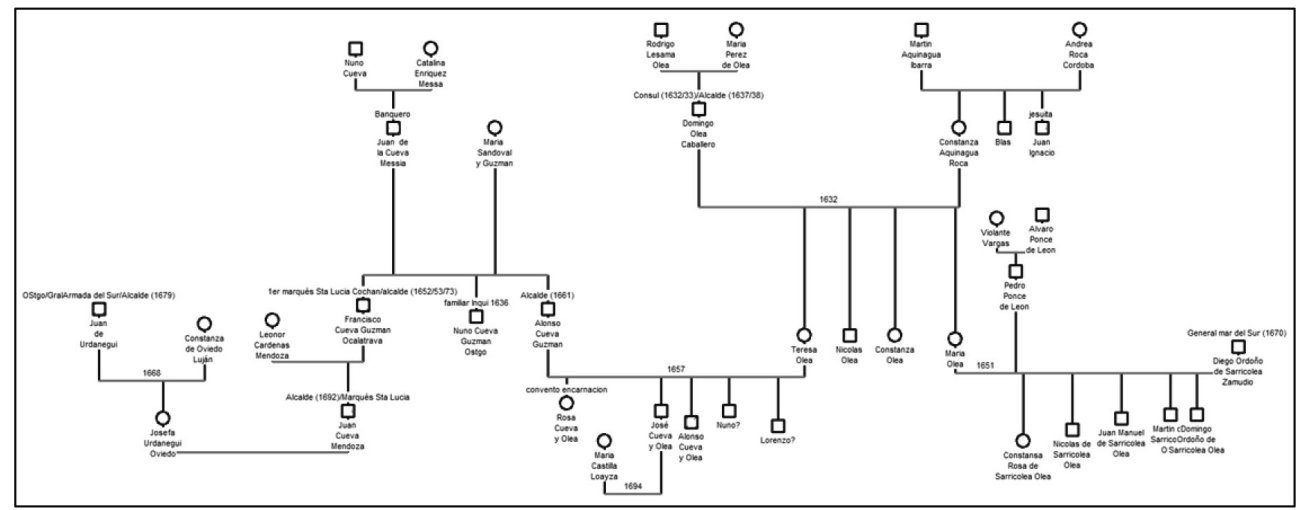

97 Elaboración propia en base a los registros parroquiales del virreinato, consultados en familysearch.org 
Árbol genealógico tentativo: los hermanos Larrea y su entorno familiar ${ }^{98}$.

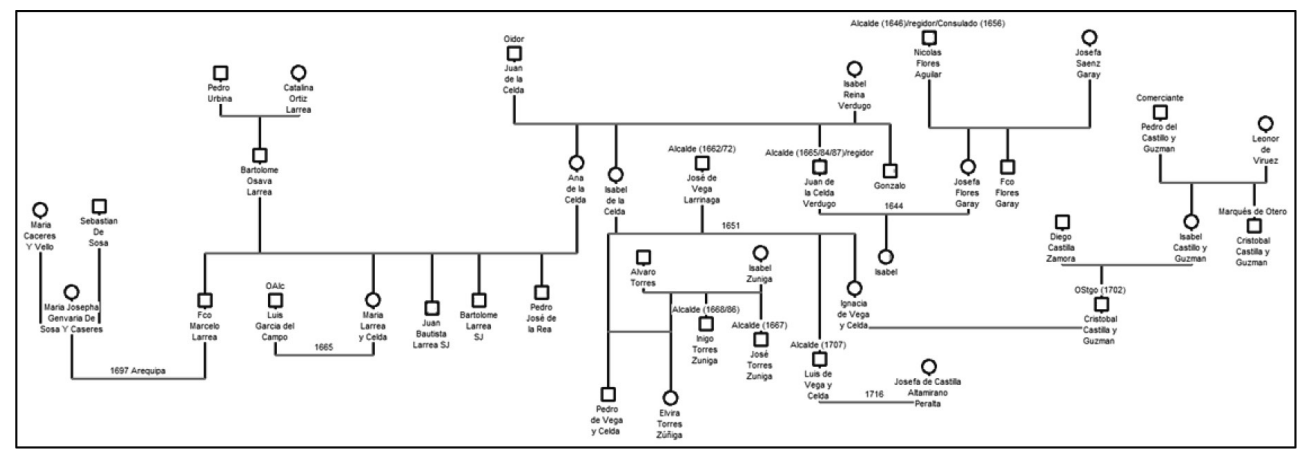

98 Elaboración propia en base a los registros parroquiales del virreinato, consultados en familysearch.org 